\title{
El origen del poblamiento celtibérico en el Alto Duero
}

\author{
The origins of Celtiberian settlement in the Upper Duero basin
}

\author{
Fernando Romero Carnicero*, Alberto J. Lorrio Alvarado** \\ *Departamento de Prehistoria, Arqueología, Antropología Social y Ciencias y Técnicas Historiográficas. \\ Facultad de Filosofía y Letras. Plaza del Campus Universitario s/n. 47011-Valladolid. \\ fromero@fyl.uva.es \\ **Departamento de Prehistoria. Universidad de Alicante. 03080-Alicante. \\ alberto.lorrio@ua.es
}

Recibido: 18-11-2010

Aceptado: 16-03-2011

\begin{abstract}
RESUMEN
Se parte de un rápido repaso por la geografía del Alto Duero y la ocupación del mismo a lo largo de la Prehistoria Reciente para, a continuación, teniendo en cuenta la dualidad de asentamientos documentados, castros y poblados, y su diferente geografía - los primeros en las estribaciones meridionales del Sistema Ibérico y los segundos en el territorio soriano localizado al sur del Duero-, analizar su posible orientación económica, en virtud de los recursos de cada zona, y el porqué de su contrapuesto interés por ocupar emplazamientos defensivos y reforzarlos con obras artificiales. Un seguimiento historiográfico viene a recordar, a continuación, las diferentes interpretaciones que han merecido castros y poblados, así como las necrópolis que, conocidas de antiguo, cabe asociar hoy a estos últimos; sus diferentes características obligan a pensar en culturas y, posiblemente, grupos étnicos diferentes. Seguidamente, y con carácter más arqueográfico, se contemplan los asentamientos, arquitectura defensiva y doméstica y rasgos materiales más destacados de uno y otro grupo, para concluir con un estudio análogo de las necrópolis.
\end{abstract}

Palabras clave: Alto Duero. Primera Edad del Hierro. Castros. Poblados. Necrópolis celtibéricas.

\begin{abstract}
After a review of the geography of the Upper Duero basin and its human occupation during the later prehistoric period, the paper analyses the economic orientation of the known settlements in the area. A duality is firstly recorded in the sites, hill forts and villages, the first occupying the southern foothills of the Iberian mountain range and the second located in the Sorian territory south of the Duero river. An examination is made of the relations between the economic system and the local resources, and on the reasons for the aforementioned settlement duality and the origin of artificial defensive architecture in some of the sites. The different archaeological interpretations of this problem, and of the cemeteries associated to the settlements, known since long ago, are exposed subsequently. The presence of different 'cultures' or 'ethnic groups' in the area appears as a necessary conclusion of the whole process. Lastly, the different features of each group-settlement patterns, defensive systems, domestic architecture, material culture and burial customs - are described.
\end{abstract}

KeY words: Upper Duero Valley. Early Iron Age. Hillforts. Settlements. Celtiberian Cemeteries.

Sumario 1. Un poco de Geografía y algo de Historia. 2. Castros y poblados ¿dos paisajes - dos economías? 3. Antes de seguir adelante ... 4. Sobre la ocupación del territorio y su materialización. 5. El mundo funerario. 


\section{Un poco de Geografía y algo de Historia}

Hasta no hace tanto tiempo cualquier aproximación histórica a lo acontecido en los comedios del primer milenio a.C. en el Alto Duero, momento en el que se apreciaba la presencia de las primeras poblaciones estables en el sector, contemplaba la disociación, geográfica entre otras, de dos grupos de yacimientos arqueológicos, por lo demás diferentes: los poblados que, situados en lugares estratégicos y dotados de defensas artificiales, denominamos castros y las necrópolis llamadas posthallstátticas, cementerios en los que los difuntos eran enterrados previa cremación de sus cadáveres (Taracena 1941: 12-16).

Ello porque en tanto los primeros ocupaban el reborde montañoso del norte de la provincia de Soria, lo que los geógrafos reconocen como "Sector Ibérico Septentrional", o "Ramal Septentrional del Sistema Ibérico", las segundas se desperdigaban por la "Depresión Central del Duero" y aún, más al sur, por el "Sector Ibérico Meridional", la tercera de las grandes unidades estructurales que, a resultas de la evolución geológica, configuran físicamente el marco geográfico soriano.

Y es precisamente en el ámbito territorial de la actual provincia de Soria en el que centraremos nuestra atención en estas páginas (Bachiller y Sancho 1990; Calavia 1990), por más que el mismo no se corresponda sensu stricto con aquél del Alto Duero a que se refiere su título.

Basta recordar en la línea de lo apuntado que en torno a un 30 por 100 de los poco más de $10.000 \mathrm{~km}^{2}$ que tiene Soria vierten sus aguas al Ebro. En el sector nororiental, por donde discurren los cursos del Cidacos, el Alhama y su afluente el Linares, y el Queiles, se conocen algunos castros (Alfaro 2005), pero curiosamente su dispersión viene a coincidir con la del correspondiente límite provincial, lo que en alguna medida nos obliga a tenerlos presentes. Otro tanto ocurre en el Sureste, por donde fluyen el Jalón y los afluentes de su cabecera, con evidentes puntos de contacto con la zona del Alto Tajo, según ponen de manifiesto las necrópolis omnipresentes en ambos territorios, razón por la cual son objeto de atención en otro trabajo de este mismo volumen, por lo que aquí nos referiremos a ellas en la medida de lo estrictamente necesario; por idéntico motivo, pero sobre todo porque han de considerarse inéditos, en la medida en que poco más que de su existencia sabemos (Jimeno y Arlegui 1995: 104, fig. 2a), prescindiremos aquí de aquellos castros que, en número apenas superior a la docena, han sido descubiertos en esta misma zona a resultas de las prospecciones llevadas a cabo para la elaboración del Inventario Arqueológico Provincial.

La orogenia alpina, cuya secuencia de plegamientos y fracturas es responsable de la orla montañosa y de la gran cuenca central y otras fosas tectónicas menores, la acción erosiva posterior, a la que se debe el arrasamiento de las cumbres y el relleno de las diferentes cubetas, $\mathrm{y}$, finalmente, el basculamiento del zócalo hacia el Oeste, lo que provocó que el Duero, tras un primer quiebro a su paso por Soria, la conocida "curva de ballesta" machadiana, y otro a la altura de Almazán, se dirigiera finalmente hacia el Atlántico, terminaron por configurar el territorio que aquí nos ocupa. Los afloramientos superficiales corresponden esencialmente al Secundario en los dos ramales ibéricos, en tanto que los de la unidad estructural central pertenecen a depósitos terciarios del Mioceno.

El aspecto achatado que, excepción hecha de las grandes cumbres, ofrecen los macizos del Sistema Ibérico unido a la completa colmatación de las tierras interiores hacen que los desniveles altitudinales no sean elevados y que, por el contrario, sí lo sea la altitud media, que se sitúa en $1.100 \mathrm{~m}$. En efecto, más de la mitad del territorio provincial alcanza entre los 1.000 y $1.200 \mathrm{~m}$ de altitud, situándose por encima y por debajo de los valores citados, respectivamente, en torno a un 15 y algo más del 20 por 100 del mismo; en el primer caso sólo una mínima parte de esa superficie supera los 1.400 $\mathrm{m}$, en el segundo rebasa siempre los 800 .

Dicha elevada altitud media y la disposición periférica de las alturas mayores hacen que la provincia de Soria goce de un clima extremado, frío y seco. La amplitud térmica a lo largo del año, y aún la oscilación diaria, es muy acusada, pues los inviernos son largos y crudos, registrando frecuentes heladas que se prolongan en otoño y primavera, y los veranos son cortos y frescos. Las precipitaciones medias oscilan entre los 500 y $800 \mathrm{~mm}$ anuales, 
y se concentran en los meses de primavera y otoño. Ni que decir tiene que las condiciones extremas se suavizan en las comarcas sedimentarias centrales haciendo que el clima sea más benigno.

El escenario descrito no es otro que aquél en el que vivieron los habitantes de los castros y quienes fueron enterrados en los cementerios inicialmente mencionados. Aquéllos vienen considerándose los primeros ocupantes sistemáticos de la serranía soriana y otro tanto podría decirse, en relación con las tierras del centro y mediodía, respecto de los segundos, a los que es preciso sumar hoy a quienes paralelamente se asentaban en una serie de poblados vecinos, con los que obviamente deben relacionarse. Denuncian su vocación de permanencia en el territorio las inversiones, sin duda colectivas, llevadas a cabo para erigir las murallas y otros sistemas defensivos en el caso de los castros de la serranía, y en el de los poblados y necrópolis la dilatada vida de muchos de ellos, a lo largo de toda la Edad del Hierro. Esto se aprecia tanto más si se quiere en la media en que nos consta que el Alto Duero, a juzgar por la escasez de vestigios documentados, debió de sufrir una crisis poblacional durante el Bronce Final; no quiere decir ello, sin embargo, que nuestros protagonistas fueran los primeros ocupantes intensivos del territorio, lo que queremos resaltar es que fueron los primeros habitantes estables del mismo.

En efecto, según se desprende de la documentación arqueológica (Jimeno 1984a; Jimeno 1985: 96-105; Jimeno y Fernández Moreno 1992; Garrido-Pena 2000; Jiménez-Guijarro 2010), el primer poblamiento intensivo se registra durante el Neolítico y viene a consolidarse, a continuación, en el Calcolítico, momentos ambos en los que para los establecimientos parecen preferirse las zonas serranas norteñas mejor que las llanas y más fértiles del Duero. Iniciado el segundo milenio a.C. asistimos a un notable cambio, ya que las tierras antes densamente ocupadas apenas si deparan ahora otra cosa que piezas metálicas aisladas, en tanto que el poblamiento se concentra en los valles del Duero y del Jalón y en las parameras ibéricas limítrofes con la provincia de Guadalajara, por un lado, y, por otro, muestra una clara diversificación, al documentarse ocupaciones en cueva y al aire libre, y en este último caso en llano o sobre cerros claramente destacados. En la nueva estrategia de ocupación del espacio se ha querido ver un intento de ampliación e intensificación de las bases de subsistencia y la naciente competitividad por el control de los recursos; en cualquier caso, parece tratarse siempre de establecimientos de corta duración.

Así, durante el Bronce Antiguo, contamos en primer lugar con asentamientos sobre ligeros altozanos próximos a los ríos que, como El Perchel de Arcos de Jalón o El Guijar de Almazán, es preciso vincular con inhumaciones individuales en fosa campaniformes tipo Ciempozuelos, como la recuperada en Villar del Campo. El Parpantique de Balluncar puede servir de ejemplo para toda una serie de poblados de nueva planta, que localizados al sur del Duero y en torno al Jalón y sus afluentes, en las zonas de contacto entre los páramos y los valles, se asientan sobre cerros estratégicamente situados y bien defendidos naturalmente, $\mathrm{y}$ que a alturas de entre 1.000 y $1.100 \mathrm{~m}$ se alzan de 40 a $100 \mathrm{~m}$ sobre las tierras circundantes; en su interior, las viviendas, rectangulares, divididas en dos estancias y de unos $30 \mathrm{~m}^{2}$ de superficie, tal y como se ha podido documentar en el yacimiento de referencia citado, se disponen en torno al cerro dejando el espacio central libre; pequeños covachos y abrigos de las laderas de estos cerros dieron cobijo a las inhumaciones de sus muertos (Jimeno, Fernández y Revilla 1988). Finalmente se aprecia una generalizada ocupación de hábitats trogloditas, tal y como atestiguan las cuevas del Asno en Los Rábanos y del Roto en Ligos; algunos de estos espacios se utilizaron también como lugar de enterramiento. Mención aparte requiere Cueva Maja de Cabrejas del Pinar por tratarse de un santuario; en los diferentes espacios de su interior se han identificado grabados rupestres y recuperado cerámicas, ídolos-colgantes y otros objetos asociados a hoyos y círculos de piedras (Gómez-Barrera 1992: 50-89). Por lo que a los materiales arqueológicos se refiere, si en los yacimientos del primer grupo son habituales las cerámicas incisas del campaniforme Ciempozuelos, en los poblados en alto y en las cuevas las especies lisas o las decoradas con cordones aplicados y motivos impresos son la norma. 
A partir de mediados del segundo milenio a.C. y durante el período que conocemos convencionalmente como Bronce Medio asistimos a una uniformización cultural de toda la Meseta; uniformización que viene impuesta no tanto por el carácter de los asentamientos, similares a los anteriores en cuanto a la diversidad de emplazamientos se refiere, lo que abundaría en la generalización de la economía mixta, cuanto por sus ajuares domésticos y en particular por sus cerámicas: lisas o decoradas con cordones aplicados e impresiones, pero sobre todo ahora con técnica incisa y motivos diversos entre los que destacan los "en espiga". La analogía de estos materiales con los recuperados en el nivel inferior del castro abulense de Las Cogotas, en Cardeñosa, ha permitido identificar la cultura que, tomando su nombre, denominamos $\mathrm{Co}$ gotas I (Abarquero 2005), cuyo floruit tendrá lugar en el Bronce Final y cuyos inicios, también conocidos como fase Pre/Proto-Cogotas $I$, coinciden con el momento que nos ocupa.

De entre los yacimientos sorianos correspondientes a esta fase, muy inferiores en número respecto de los del Bronce Antiguo, destaca el de Los Tolmos de Caracena, un asentamiento temporal que fue ocupado en los meses de primavera-verano. Su excavación permitió recuperar dos fondos de cabaña de planta rectangular y superficies de unos 6 y $15 \mathrm{~m}^{2}$, cuyas paredes y techumbre, de postes trabados con barro, sustentaba una viga horizontal apoyada a su vez sobre sendos postes; los hogares, circulares y delimitados por piedras, se sitúan al exterior y junto a las puertas, que se abrían al Este. Sus habitantes practicaron una economía mixta consistente en la cría de ovicaprinos, bóvidos y caballos y el cultivo del cereal, sin desdeñar la captura de ciervos, jabalíes y liebres. El yacimiento ha deparado también dos enterramientos en fosa, en los que los inhumados aparecían en posturas muy forzadas: uno de ellos albergaba a dos adultos y un recién nacido; el segundo, localizado delante de una de las cabañas, a un individuo de entre 18 y 20 años (Jimeno 1984b; Jimeno y Fernández Moreno 1991).

El descenso poblacional acusado en el Bronce Medio se vio acentuado durante el Bronce Final, ya que tan sólo algunas cerámicas decoradas con las técnicas del boquique y excisa, del más puro estilo Cogotas I, permiten entender los respectivos lugares de hallazgo como asentamientos cogotianos y atribuirlos a este momento. Y si los lugares citados se localizan en el centro y sur de la provincia van a ser las estribaciones septentrionales del Sistema Ibérico las que prodiguen hallazgos metálicos, bien sea en forma de depósitos, como en el caso de Covaleda, ya a través de piezas aisladas.

Menos halagüeño es aún si cabe el panorama de los primeros tiempos de la nueva Edad, ya que apenas si podemos vincular a los mismos más que algunos vasitos que, aunque decorados también con excisiones, difieren notablemente, tanto por sus sintaxis decorativas como por sus propias formas, de aquellos de Cogotas I que acabamos de mencionar. Dichas piezas, documentadas fundamentalmente en Quintanas de Gormaz y Castilviejo de Yuba, tienen réplicas adecuadas en ejemplares bajoaragoneses de Campos de Urnas de la Edad del Hierro que se fechan en el siglo VII a.C. (Ruiz Zapatero 1984). Algunos hallazgos recientes han venido a arrojar algo de luz sobre esta "etapa oscura", planteando un escenario no muy diferente del que viene observándose en otras zonas de la Meseta Oriental, como la comarca de Molina de Aragón, en Guadalajara (Ruiz Zapatero y Lorrio 2005: 658-659). Este podría ser el caso de El Palomar (Almajano), un asentamiento en llano, seguramente integrado por una aglomeración de cabañas, que ha proporcionado un interesante conjunto de materiales de superficie, principalmente cerámicos, en el que destacan las especies decoradas, y dentro de éstas, las acanaladas, las incisas $\mathrm{y}$, aunque con un único fragmento, las excisas, cuyos motivos y formas cabe relacionar con los citados influjos de Campos de Urnas llegados desde el Valle del Ebro (Morales y Bachiller 2007). Destaca igualmente el cementerio de San Pedro, en Oncala (Tabernero, Sanz y Benito 2010: 391-395, fig. 2), que ha proporcionado un total de veintidós tumbas de incineración en hoyo, habiéndose recuperado algunas estelas caídas en sus inmediaciones y un escaso ajuar integrado por algunas lascas de sílex — tumbas II y III-, una anilla de bronce - tumba XX-y los restos de las urnas cinerarias realizadas a mano - tumbas IX y XIII-. Su interés es indudable, pues viene a confirmar que la introducción del ritual 
incinerador en las tierras sorianas sería muy anterior a lo que se venía sospechando, dado que el cementerio ha proporcionado dos fechas radiocarbónicas que proporcionan sendos intervalos de mayor probabilidad a dos sigmas de $1266-1008$ y $1260-910$ cal. a.C. (Fig. 2, 1), sin que el material recuperado permita realizar mayores precisiones cronológicas.

Visto todo lo cual, y sin dejar de tener presentes algunos de los aspectos anunciados páginas atrás, no debe extrañarnos que cuanto acontece a partir de la última fecha citada, cuando vemos surgir nuevos y numerosos castros y poblados por toda la geografía soriana, constituya el primer poblamiento estable en el Alto Duero y la base de las futuras ciudades celtibéricas.

\section{Castros y poblados ¿dos paisajes - dos economías?}

Las anteriormente referidas condiciones climáticas, aunque relativas al momento actual, no deben diferir mucho de las que tuvieron que soportar los habitantes del Alto Duero durante la primera Edad el Hierro, pues dicho clima, definido como mediterráneo frío, es el que impera en la región desde que se iniciara, en torno al 800 a.C., el período climático Subatlántico. No podemos decir otro tanto, por desgracia, en lo que a las condiciones ambientales se refiere, pues carecemos en este caso de estudios como los llevados a cabo para el Duero Medio (Delibes, Romero y Morales 1995); aun así, ciertos datos derivados de los mismos y concordantes con la información que aporta la geografía parecen lógicamente aplicables al curso alto del río, razón por la cual no desaprovecharemos la ocasión de tenerlos en cuenta aquí una vez más.

Cabe pensar en dicho sentido que en el primer milenio a.C. los cursos fluviales tuvieran caudales mayores y más irregulares que hoy y suponer, pues además debían discurrir algunos metros por encima de su actual nivel, hubiera inundaciones más o menos periódicas, lo que supondría un ambiente en general más húmedo. Abundarían en ello algunas referencias del historiador Apiano, cuyo libro Sobre Iberia, VI de su Historia Romana, constituye fuente esencial para la guerra de Numancia, máxime ello si, como parece, tuvo como fuente principal cuando no única, ya que él escribió su obra en la segunda mitad del siglo II d.C., a Polibio, testigo presencial de los acontecimientos y, por tanto, directo conocedor del territorio. Narra así Apiano (Iber., 91) que el Duero a su paso por Numancia era ancho y muy impetuoso, lo que impidió a Escipión construir un puente, y cómo los numantinos conseguían romper el cerco, entre otras formas, sirviéndose de barcos de vela, dándonos con ello idea de su navegabilidad; inmediatamente antes (Iber., 90) cita la existencia de una laguna en las inmediaciones de la ciudad.

Es innegable que en un mundo marcadamente tradicional como es el soriano las más importantes transformaciones ambientales han venido de la mano del progreso y que, por tanto, han tenido lugar desde mediados del siglo XX hasta la actualidad. No debe entenderse tal, sin embargo, en el sentido de que pueda extrapolarse la situación previa al momento citado más de dos mil quinientos años atrás. Y ello porque si bien es cierto, por un lado, que pudiéramos sentirnos tentados de proyectar a los tiempos que nos ocupan $-\mathrm{y}$ por tanto mucho más allá de lo que pretende Margarita Calavia remontándolos a la Edad Media- varios de los aspectos contenidos en su descripción urbanística de cualquiera de los múltiples núcleos rurales sorianos existentes en torno a la fecha mencionada, y aun los rasgos esenciales de las prácticas agrícolas mantenidas asimismo durante centurias, no lo es menos, por otro, como se encarga de recordarnos igualmente la mencionada geógrafa, que difícilmente reconocería hoy un viajero del siglo XVIII muchas de las zonas recorridas de la provincia de Soria, dados los cambios habidos en la distribución de sus bosques (Calavia 1990: 140-157).

Si tenemos en cuenta que lo señalado en último lugar es en buena medida consecuencia de las modificaciones sufridas por el paisaje agrario parece lógico que nos refiramos a ellas en primer lugar. La ejecución de la concentración parcelaria ha constituido el detonante de las más recientes, ya que supuso en primera instancia la transformación de algunos cientos de miles de pequeñas parcelas, muchas de ellas cercadas, en varios miles de unidades de explo- 
tación mucho mayores; la paralela sustitución en las tareas agrícolas de la fuerza animal por la moderna maquinaria, que a partir de entonces pudo acceder fácilmente a los campos de labor, liberó no pocos pastizales al tiempo que contribuyó a aumentar la producción, algo a lo que no fue ajena, por otro lado, la introducción de los nuevos fertilizantes. Las abiertas posibilidades de aumentar la producción, y por ende los beneficios, condujeron a ganar para el agro nuevos territorios, caso de viejos eriales y antiguas dehesas boyales, pero no sólo estos, pues a ellos se incorporaron además con nuevas roturaciones bosques tradicionales de encinas y robledales fundamentalmente, de los fértiles Campo de Gómara y Tierra de Almazán en particular. En definitiva, se ha duplicado la extensión agraria provincial, algo que tampoco era nuevo en los tiempos recientes, pues ya en el siglo XIX la desamortización de Madoz supuso, aunque dentro de los sistemas de explotación ancestrales, un considerable aumento en el mismo sentido, a costa en aquella ocasión de los montes de propios; ello ha significado además, al margen de la introducción de nuevos cultivos o de la suplantación en muchos campos del habitual trigo por la cebada, un reforzamiento de la acentuada vocación agrícola cerealista provincial y de rechazo un notabilísimo descenso de la explotación ganadera, que en el caso del vacuno se ha visto reducida por encima del 50 por 100 .

Por otro lado, como anunciábamos líneas arriba, las transformaciones no han sido menores en lo que se refiere al paisaje forestal, aunque, como se desprende de la información proporcionada por el Catastro del Marqués de la Ensenada, la superficie ocupada por los bosques siga siendo hoy aproximadamente la misma que en la segunda mitad del siglo XVIII, situándose en torno a un tercio de la provincial. Los cambios afectan en esta ocasión, en primer lugar y como queda dicho en el punto anterior, a las áreas cubiertas por los bosques, ya que en tanto estos se han visto considerablemente reducidos en las comarcas centrales han sido acrecentados notoriamente en Pinares y Tierras Altas; en segundo lugar, por lo que tiene que ver con las especies arbóreas, puesto que Pinus, sylvestris y pinaster principalmente, y otras coníferas, otrora mi- noritarias, han ido ganando terreno e impuesto su predominio en detrimento de las diferentes especies de Quercus: encinas sobre todo, pero también rebollos y quejigos.

No resulta difícil deducir de cuanto queda dicho hasta aquí cómo hasta no hace demasiadas décadas las gentes sorianas, profundamente ruralizadas y agrupadas en numerosos y pequeños núcleos de población, desarrollaron un régimen de vida campesino, de carácter en los más de los casos subsistencial. El potencial ecológico de cada nicho imponía la orientación económica principal: la agricultura en el valle del Duero y otras cubetas sedimentarias menores y la ganadería, de vacuno en el valle del Tera y lanar trashumante en La Serranía, antiguo e importante núcleo de La Mesta, manteniendo así una tradición arrastrada centuria tras centuria. De ahí que no deba de extrañarnos que apenas descubiertos los primeros castros, y desde una perspectiva un tanto determinista desde el punto de vista geográfico y seguramente histórico también, se atribuyera a sus habitantes un "medio de vida pastoril" trashumante y se viera en el ganado lanar su "principal fuente de riqueza" (Taracena 1929: 3-6); ni que, más recientemente, se haya hecho descansar en la agricultura la base económica fundamental de quienes ocuparon los poblados de las tierras llanas en torno al Duero (Revilla y Jimeno 1986-87: 100-101).

Ello no creemos que deba de entenderse, en ningún caso, desde un punto de vista reduccionista, es decir adjudicando a uno u otro grupo una economía diferente, pastoril en un caso y agrícola en el otro, exclusiva y por tanto especializada, sino entendiendo más bien que cada uno de ellos practicó ambas, aunque incidiendo en cada caso en la explotación de aquél recurso que más favorablemente le ofrecía el correspondiente territorio.

En páginas anteriores hemos tenido ocasión de comentar cómo la economía mixta fue generalizándose hasta consolidarse a lo largo de la Edad del Bronce, y el testimonio ofrecido por Los Tolmos de Caracena, localizado en un ambiente propicio para el desarrollo de la ganadería, es bien elocuente en relación con lo dicho. Para el momento que nos ocupa, y pese a la comentada penuria de datos de que disponemos en este sentido, pueden sernos 
de utilidad las escasas, pero igualmente significativas, referencias proporcionadas por los análisis arqueofaunísticos de las cabañas inferiores de El Castillejo de Fuensaúco (Bellver 1992), un poblado situado a escasos kilómetros al este de Soria capital, y por tanto en tierras favorables a las prácticas agrícolas.

Dichos análisis han permitido identificar, además del cerdo, vaca, caballo, oveja y cabra, sin que sea posible deducir porcentajes preferentes ya que el número mínimo de individuos reconocidos de cada especie es, en concordancia con lo reducido de la muestra, pequeño y muy parejo; en cualquier caso, el dato es bastante ilustrativo si nos atenemos, como mínimo, a lo diversificado de la cabaña ganadera. Es más, la recuperación de restos de ciervo obliga a pensar también en este caso, al igual que en Los Tolmos, en la importancia que la caza seguía manteniendo en la aportación proteínica a la dieta de las gentes del Primer Hierro; ello implicaría además la posibilidad de un no muy alejado bosque de frondosas y probablemente una distribución más homogénea de las manchas arbóreas por el Alto Duero, aspecto este último que viene a ilustrar también, una vez más, el clásico alejandrino cuando al comentar la campaña de Metelo contra Numancia nos dice que ésta estaba rodeada de bosques muy densos (Apiano, Iber., 76).

$\mathrm{Y}$, sin embargo, algo ha cambiado respecto del Bronce Medio-Final. Es cierto que una dualidad análoga a aquélla de que partíamos, es decir castros-sistemas defensivos-economía ganadera/poblados en llano-ausencia de defensas-economía agrícola, se ha venido planteando en relación con los yacimientos Cogotas I; asimismo, que la arqueología se ha encargado de demostrar, al igual que en el repetido caso de Los Tolmos, que practicaron una economía mixta. Ahora bien, no terminaba de entenderse del todo cómo una cultura con tan alta densidad de yacimientos y explotando en régimen intensivo su territorio no hubiera entrado en conflicto, sino que, por el contrario, tuvo tan notable éxito como denuncia su larga duración. Y fue María Dolores Fernández-Posse (1998: 112-120) quien, en aras de solventar este dilema, nos ofreció una posible explicación; nos recordaba en primer lugar dicha investigadora el carácter temporal, aunque en múltiples casos de ocupación recurrente, de los asentamientos cogotianos, es decir la movilidad de sus gentes, con la consiguiente multiplicación de las estaciones, que deben por otra parte escalonarse a lo largo de la vida de la cultura; dedujo a partir de ello una baja densidad de población y sugirió que la explotación de su vasto y diversificado territorio, en tanto que en los distintos nichos ecológicos incidirían en los respectivos recursos, fuera extensiva, lo que evitaría la competencia entre los diferentes grupos humanos y explicaría lo invariable de su cultura material a lo largo de aproximadamente medio milenio.

Frente a ello, los habitantes de nuestros poblados, ya se trate de castros o no, muestran desde el primer momento clara intención de permanencia no sólo ya en el territorio, y en un territorio reducido si lo comparamos con el de Cogotas I, sino en el lugar previamente elegido para su asentamiento. Y lógica parece, por otro lado, por más que no parezca venir al caso de momento, la discriminante elección del espacio geográfico en cada caso, puesto que mientras que aquellos grupos que muestran despreocupación por la defensa eligen el valle del Duero y las zonas sedimentarias, más llanas y abiertas, los que buscan defenderse, y emprenden la erección de obras artificiales, prefieren las zonas serranas, buscando sin duda el concurso que la propia geografía les ofrece para tal fin.

Ahora bien, conviene no perder de vista, volviendo al hilo del argumento, que uno y otro territorio ofrecen asimismo recursos y posibilidades de explotación diferentes y que ello debió de ser igualmente tenido en cuenta por quienes, a juzgar por los datos de que disponemos, ocuparon el mismo enclave entre un siglo y quinientos años, incluyendo en este último caso su pervivencia en parte al menos de la segunda Edad del Hierro. Ambos aspectos vienen a implicar una vocación económica distinta, aunque no exclusiva como hemos visto, y una explotación intensiva del medio, dato este último que vendría a requerir a su vez una no excesiva densidad de población, so pena de introducir el desequilibrio y las fricciones sociales correspondientes. 


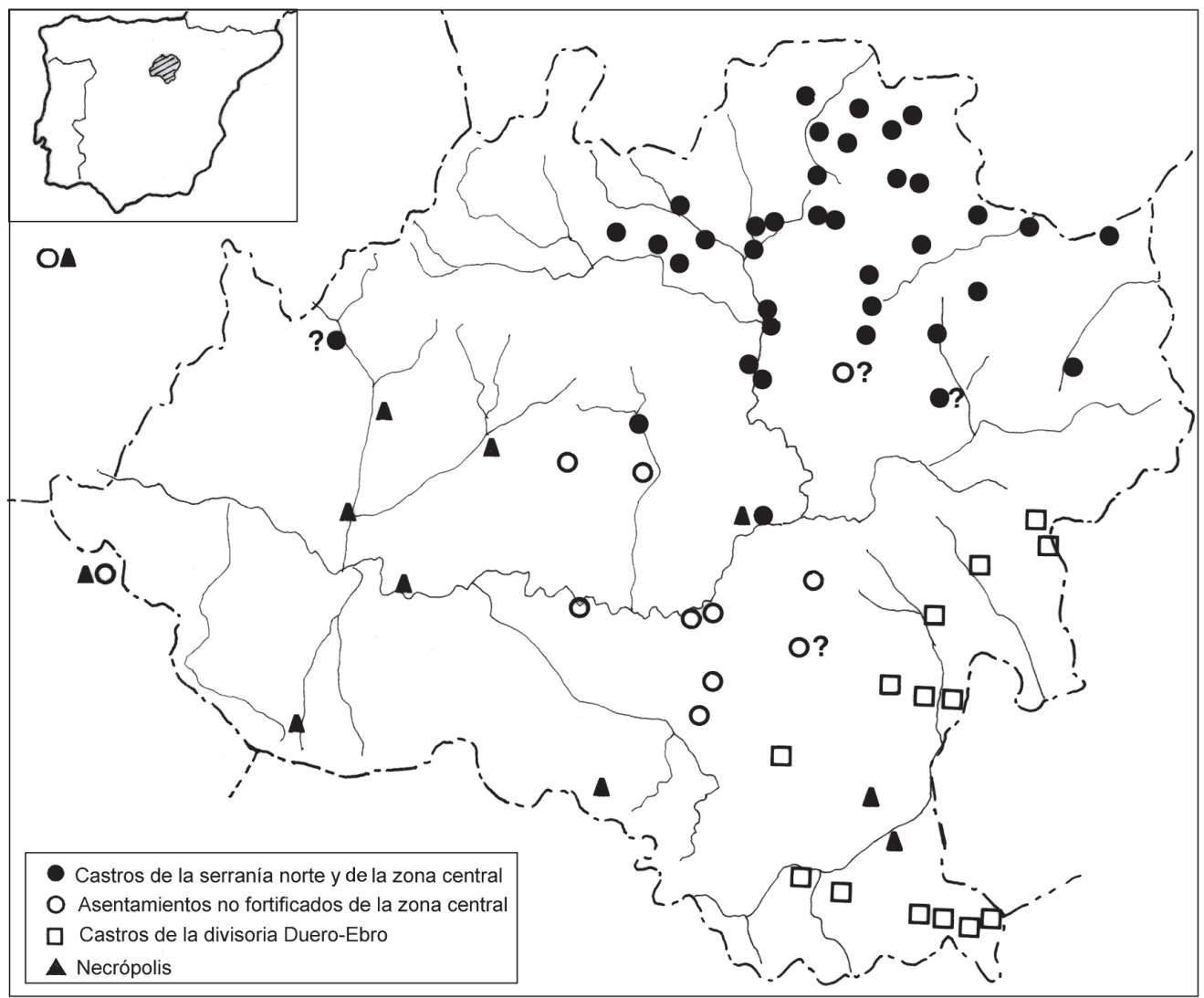

Figura 1.- El poblamiento de la primera Edad del Hierro en el Alto Duero (según Jimeno y Arlegui 1995, completado a partir de Alfaro 2005 y Tabernero et al. 2010).

Un mapa de dispersión de los yacimientos de la primera Edad del Hierro en el Alto Duero pudiera dar la impresión de una densa ocupación del mismo (Fig. 1), pero en el fondo no deja de ser más que eso: una impresión; ello deriva esencialmente de su comparación con el correspondiente al Bronce Final, pero contrasta igualmente, aunque en sentido inverso, si se toma como referencia el relativo a la etapa inmediatamente posterior (Jimeno y Arlegui 1995: figs. 2 a 4, 9 y 10). No parece por tanto que deba pensarse en desequilibrios entre población y recursos durante esta fase, aunque quizá no haya que dejar de valorar esta posibilidad a la hora de explicar el hecho contrastado de que muchos de los castros de la serranía norte fueran abandonados al final de la misma.
De ser así las cosas tampoco habría que pensar en conflictos sociales derivados de la competencia por los recursos y los respectivos territorios de explotación, incluso a nivel local; pero en dicho caso ¿cómo explicar las defensas de que se dotan quienes habitan las zonas serranas? En principio bastaría con recordar que sólo ellos, como tendremos ocasión de detallar más adelante, construyen obras defensivas de envergadura, en las que junto a potentes murallas, levantan campos de piedras hincadas o excavan fosos, por lo que deberíamos de deducir que de existir tales conflictos sería entre ellos mismos, y que no contamos en el estado actual de la investigación con argumentos suficientes para valorar el papel jugado en este sentido por las gentes que viven más al sur, sobre todo teniendo en cuenta que, junto a la ausencia en 
la mayoría de sus poblados de los elementos defensivos, sus necrópolis ponen de manifiesto la presencia de un estamento de tipo guerrero, hasta ahora no detectado en el ámbito castreño del norte provincial (Lorrio 1997: 269).

Por otro lado, y como han venido a demostrar las últimas campañas de excavaciones llevadas a cabo en yacimientos de uno u otro grupo, tales como el Castro del Zarranzano, en Cubo de la Sierra, o El Castillejo de Fuensaúco, los incendios identificados en los mismos, tan jaleados por ciertos investigadores como evidencias de destrucciones generalizadas, no dejan de afectar a puntos concretos y responder, por tanto, a accidentes localizados y puntuales. Y tampoco cabe contemplar que la acumulación de sistemas defensivos sea índice de una jerarquización espacial, pues si bien es cierto que algunos yacimientos que cuentan con todas ellas pudieran ser algo mayores o parecer más importantes, ello no se debe a otra cosa que a que, como ocurre en el caso de El Castillejo de Castilfrío de la Sierra, sean más conocidos.

Cabe preguntarse entonces el porqué de tales empresas constructivas si, como parece, no tenían una finalidad claramente defensiva, en el sentido militar que a toda fortificación se sobreentiende. Ello podría explicarse si se prescinde de tal justificación militar y se contempla, entre otras varias posibilidades en las que no cabe detenerse por ahora -téngase en cuenta al respecto un reciente trabajo de Gonzalo Ruiz Zapatero (2003) - , que lo que se trataba de salvaguardar no fueran las personas sino los bienes, los rebaños en este caso, y no necesaria ni exclusivamente de otras personas. Vistas así las cosas, la necesidad de asumir esfuerzos colectivos de tal envergadura, que suponemos difícilmente entendibles para quien no conozca este tipo de yacimientos, vendría indisolublemente unida a su vocación económica; una y otra deberían entenderse en definitiva como rasgos culturales del grupo correspondiente, de la misma manera que la ausencia de necesidades defensivas en la mayoría de los casos y las prácticas fundamentalmente agrícolas caracterizarían a las gentes que ocupan los poblados de las tierras más meridionales, y aún, como se ha llegado a insinuar, como distintivo étnico. Y bastaría recordar en este sentido la vigencia del clásico trabajo de Blas Taracena (1933) dedica- do a los pelendones, en el que les atribuye la cultura de los castros sorianos, para entender que tras el descubrimiento de los primeros poblados en llano en la comarca adnamantina se sugiriera su adscripción a los arévacos (Revilla y Jimeno 1986-87: 101).

En virtud de lo dicho, unos y otros constituirían los primeros modeladores importantes del paisaje del Alto Duero, iniciándose con ellos un proceso que, cada vez más intenso y radical a medida que avanzaba el tiempo, alcanza a nuestros días.

\section{Antes de seguir adelante...}

Cuando en los inicios mismos del presente texto llamábamos la atención sobre la disociación castros/necrópolis posthallstátticas insinuábamos al tiempo otras posibles; con posterioridad, y a lo largo de las páginas siguientes, dicha contraposición ha venido a ser sustituida por otra en la que los poblados ocupaban el antiguo lugar de los cementerios. Ello requiere, sin duda, una explicación y quizá sea éste un momento prudente para abordarla. Cabría incluso, planteándola a muy grandes rasgos, resumirla en los siguientes términos: castros y necrópolis no eran en principio estrictamente coetáneos, pues estas últimas venían a iniciar su andadura poco tiempo antes de que se abandonaran muchos de aquellos; ahora bien, comprobada la mayor antigüedad de las primeras tumbas y descubierta al tiempo una serie de poblados, en el mismo ambiente geográfico y de cronología análoga, pudieran darse por resueltos cuando menos dos problemas: el de enfrentarnos a castros y necrópolis que además de no ocupar el mismo espacio geográfico no eran contemporáneos y el de poder atribuir dichos cementerios a los habitantes de los poblados. Las contradicciones de la vieja disociación quedarían replanteadas en una nueva y más lógica: castros/poblados-necrópolis, como dos realidades diferentes de la primera Edad del Hierro en el Alto Duero que, como hemos visto además, pueden explicarse desde el punto de vista cultural y traducir diferencias étnicas, aunque como veremos la presencia de algún asentamiento fortificado en las tierras del centro-sur provincial venga a matizar en parte tal dicotomía. 
Las cosas no son tan sencillas, por tanto, de ahí que merezca la pena dedicar algún espacio si no tanto a esbozar una explicación satisfactoria a formular, cuando menos, las muchas dudas y dificultades que todavía plantean. Y sin embargo tampoco podremos extendernos mucho en ello, so pena de tener que prescindir en demasía de los aspectos más arqueográficos a los que necesariamente habremos de referirnos después; de ahí que en este apartado, más que en ningún otro, remitamos a otras posibles lecturas.

En la Carta Arqueológica señalaba ya claramente Blas Taracena (1941: 14-15) que la "ruda cultura pastoril" de los castros podía fecharse entre los siglos VI y IV a.C., en tanto que las más antiguas necrópolis, cuyo calificativo de posthallstátticas de tan evidentes connotaciones crono-culturales debemos a Pedro Bosch Gimpera (1932: 576-579), iban de la primera mitad del IV a comienzos del III a.C. Les seguían según el mencionado arqueólogo otras que, por saber a través de los textos clásicos que dicho territorio está ocupado a partir de entonces por los arévacos, no duda en denominar, siquiera sea implícitamente, celtibéricas. El nuevo calificativo, elástico donde los haya (Lorrio 1997: 33-52; Burillo 1998: 65-120), se atiene aquí, por tanto, al marco geográfico y los límites temporales derivados de los textos históricos antiguos.

A lo largo de las últimas décadas ha venido comprobándose, sin embargo, la mayor antigüedad de estas necrópolis, por un lado, y la larga vida de muchas de ellas, por otro (GarcíaSoto 1990; Lorrio 1997: 262-289; Argente et al. 1992). Ello ha permitido entender que las variaciones formales, decorativas o técnicas sufridas por los diferentes objetos que integran los ajuares de los individuos en ellas enterrados a lo largo del tiempo, cientos de años incluso, no son sino el resultado de la evolución cultural del grupo humano correspondiente y llevado a denominarlas celtibéricas en general, al asumir que desde un principio fueron los distintos pueblos, que según los autores clásicos integraban el grupo étnico celtibérico en tiempos de la conquista romana, los que enterraban a sus muertos en ellas. Todo lo cual no es sino el resultado, en definitiva, de diversos trabajos monográficos dedicados a cementerios concre- tos o grupos de ellos (Burillo 1990), lo que ha posibilitado, a su vez, un estudio de conjunto en el que se establece la evolución interna de tales necrópolis desde el siglo VI a la romanización, largo período de tiempo del que nos interesan aquí las fases denominadas Celtibérico Antiguo y parte del Celtibérico Pleno (Lorrio 1997: 261-264 y 275-283).

Ahora bien, si la denominación celtibéricas comporta una calificación étnica, la cultura material que reflejan sus ajuares funerarios ha venido poniéndose en relación, para sus momentos inaugurales cuando menos, con aportaciones de diversa procedencia y tradiciones culturales variadas: el Mediodía peninsular, la zona del Levante y el Sureste o el Valle del Ebro (Lorrio 1997: 271), planteando por lo que respecta a este último territorio la vinculación de tales elementos con los Campos de Urnas Tardíos o de la Edad del Hierro inmediatos del Bajo Aragón y, en última instancia, del Ebro Medio; relación justificable también en este caso si nos atenemos al ritual funerario. En este sentido las necrópolis celtibéricas, tanto del Alto Duero (Romero 1984a: 85) como del Alto Tajo y Alto Jalón (Cerdeño y García Huerta 1990), han sido atribuidas en origen a grupos de Campos de Urnas Tardíos, grupos que, desde la perspectiva continuista que denuncian, no serían otros que aquellos a los que andando el tiempo conoceremos con nombres étnicos propios.

Otro tanto se ha señalado en relación con los poblados del centro provincial que, fechados entre los siglos VII y V a.C., muestran en ocasiones continuidad durante la segunda Edad del Hierro (Revilla y Jimeno 1986-87: 100); tal es el caso de El Castillejo de Fuensaúco, cuyo abandono debió de tener lugar, muy probablemente, al iniciarse las guerras celtibéricas, en torno a mediados del siglo II a.C. (Romero y Misiego 1995a). Tal y como hemos señalado con anterioridad, su descubrimiento ha llevado lógicamente a relacionarlos con las necrópolis, aunque como veremos ello no siempre es fácil cuando se desciende a vinculaciones concretas; lógico parece, por tanto, que, como se hacía en un trabajo de síntesis ya citado (Lorrio 1997: 267-268), su estudio se aborde conjuntamente con el de aquellas y se beneficien así, en cuanto habrían de considerarse según lo dicho y desde 
sus mismos inicios los hábitats celtibéricos, de la periodización establecida para las mismas.

No parece que pueda decirse otro tanto en el caso de los castros de la serranía norte, dado que desconocemos hasta la fecha sus cementerios; dicha ausencia, en la medida en que entendamos que las necrópolis, y todo cuanto ellas implican y significan, constituyen uno de los rasgos culturales distintivos y más característicos de los celtíberos, sería más que suficiente para excluirlos de tal grupo. Aunque resulta difícil creer que a estas alturas pueda atribuirse ello a los desventurados azares de la arqueología, no conviene olvidar el ya referido hallazgo, en la zona norte de la provincia de Soria, de una necrópolis de incineración, más antigua eso sí que los castros que venimos analizando, localizada con motivo de la modificación del trazado de la carretera del Puerto de Oncala a San Pedro Manrique (Tabernero, Sanz y Benito 2010: 391-392), en un paraje donde junto a materiales de difícil datación abundaban los de época romana, medieval y moderna (Alfaro 2005: 66-69).

Otro problema, que por fuerza no haremos sino mencionar, viene a agravar la cuestión; nos referimos a la identificación, ya comentada, de los castros como los asentamientos de los pelendones, una etnia cuya pertenencia a los celtíberos ha venido siendo discutida a partir de un confuso texto de la Geografía de Estrabón (III, 4, 19). Blas Taracena (1954: 200-206) los incluyó en su día en su ya clásico estudio sobre dicho grupo étnico y otro tanto han hecho no hace tanto otros autores (Bachiller y Ramírez 1993; Lorrio 1997: 33-46 y 268270; Burillo 1998: 193-199), pero no por ello el dilema deja de seguir en pie; su resolución requiere, en primer lugar, un replanteamiento de la ecuación etnia $=$ cultura arqueológica $y$, a partir de ahí, y suponiendo que siga manteniéndose ésta, el sopesar si la primacía se otorga a la documentación arqueológica, clara a nuestro juicio, o, por el contrario, a unos textos breves y escasos, además de muy tardíos. Recordaremos, con todo, en relación con estos últimos, cómo una atenta lectura de la Geographia de Claudio Ptolomeo ha llevado a Ángel Ocejo (1995) a reubicar a los pelendones más al norte y occidente de donde se venían situando habitualmente, de lo cual se desprende que su área nuclear se habría extendido por la provincia de Burgos en lugar de por la de Soria que, de esta manera, habría estado ocupada en su práctica totalidad por los arévacos; la propuesta, si bien vendría a solucionar la cuestión que venimos planteando, abre nuevos frentes que no nos podemos detener a analizar aquí.

Un problema análogo al comentado se plantea asimismo si tenemos en cuenta que en su momento los castros fueron atribuidos también a un grupo de Campos de Urnas Tardíos del Hierro (Romero 1984b: 41-42), al ser las necrópolis de incineración en urna, como su propio nombre indica, el rasgo que identifica, por encima de cualquier otro, a dicha cultura. Bastaría tener presente lo dicho por Martín Almagro-Gorbea (1986-87) en su ponencia al Coloquio Internacional sobre la Edad del Hierro en la Meseta Norte, celebrado en Salamanca en 1984, lo cual es igualmente aplicable a los poblados y necrópolis celtibéricos aquí estudiados, para recordar la prudencia que requiere el empleo del término Campos de Urnas cuando nos referimos no sólo ya a culturas de la primera Edad del Hierro de la Meseta, sino incluso del Valle del Ebro; no es de extrañar por ello que, tal y como ha sido reconocido (Romero y Misiego 1995b: 71), a lo largo de los últimos años hayamos pasado, de contemplarlos como un tal grupo de Campos de Urnas del Hierro, a hablar de una cultura de tradición o influencia de los mismos y a explicar el indudable parentesco que ofrecen ciertos elementos de su cultura material con los del mundo del Primer Hierro del Valle del Ebro, y en particular sus cerámicas, como resultado de procesos como el de deriva cultural, esbozado por Gonzalo Ruiz Zapatero (1995: 35),

Si hasta no hace excesivo tiempo el paradigma invasionista ha constituido un socorrido apoyo a la hora de explicar la presencia de grupos humanos que, como en el caso de los aquí analizados, parecían hacer acto repentino de presencia en territorios prácticamente vacíos con anterioridad, hoy se prefiere interpretar ello a partir de la evolución interna del sustrato indígena; de la misma manera, las habituales compartimentaciones temporales, motivadas casi siempre por la aparición de materiales o técnicas nuevas, han sido sustituidas por análisis de larga duración, en los que tales cambios, 
aun admitiendo fenómenos de interacción o influencias y sin llegar a negar posibles y pequeños aportes humanos, no son sino el lógico resultado de la evolución cultural del grupo humano correspondiente. Dicho proceso intelectivo ha venido recogiéndose, en los últimos veinte años y por lo que aquí interesa, en diversos estudios de síntesis y estado de cuestión (Romero 1984a; Jimeno 1985; Romero y Ruiz Zapatero 1992), lo cual no quita para que, a modo de colofón del presente epígrafe y brevemente una vez más, intentemos registrar cómo se entiende al día de hoy, en virtud de lo dicho, el mencionado proceso.

Habremos de partir nuevamente para ello de contrastar la progresiva despoblación que sufre a lo largo de la Edad del Bronce el Alto Duero con la eclosión demográfica que muestra en la primera Edad del Hierro, fenómeno que, según una propuesta de Alfredo Jimeno y Juan Pablo Martínez Naranjo (1999: 180-185), pudiera deberse a las condiciones climáticas, $\mathrm{y}$ por tanto ambientales, imperantes en cada uno de dichos momentos. En virtud de ello, y según dichos autores, el progresivo deterioro de las condiciones ambientales durante el período climático Subboreal habría obligado a las comunidades más estables del Bronce Medio, y en mayor medida a las del Bronce Final, que habitaban junto a las cuencas de los ríos las zonas situadas por debajo de los $800 \mathrm{~m}$ de altitud, a dejar de frecuentar, en sus prácticas ganaderas transterminantes, los territorios más elevados; dichos territorios se tornarían más atractivos, sin embargo, con el cambio climático que, en torno al 800 a.C. como señalamos anteriormente, dio paso al período Subatlántico, lo que sería aprovechado por los grupos del Ebro, que tiempo atrás los habían visitado temporal, aunque regularmente, para instalarse en los mismos. Ello habría tenido lugar, según dichos autores, paulatinamente y en forma de pequeños grupos, en la línea del modelo socioeconómico expansivo formulado por Gonzalo Ruiz Zapatero (1995), iniciándose así un proceso que, sin solución de continuidad, alcanza la romanización.

Dicha propuesta no deja de ser en cualquier caso, lo cual en cierta medida es lógico si se tiene en cuenta la situación de la que parte, una visión atemperada de las viejas teorías invasio- nistas. Y otro tanto podría decirse, y de hecho se ha dicho (Burillo y Ortega 1999: 131-132), del mencionado modelo socioeconómico expansivo, si bien con posterioridad su mentor, en una versión en alguna medida suavizada del mismo formulada conjuntamente con Alberto J. Lorrio - y alternativa a los planteamientos más generalistas sobre la compleja formación de la cultura céltica peninsular de Martín Almagro-Gorbea (1993) - en la que se prescinde de la explicitación concreta del proceso histórico, valoran la interacción entre el modelo social y económico que las poblaciones de Campos de Urnas del Noreste estaban imponiendo en los siglos VIII-VII a.C., y que pequeños grupos de colonos habrían ido introduciendo entre las poblaciones locales, y el importante y activo papel que dichas comunidades indígenas habrían tenido en la etnogénesis celtibérica (Ruiz Zapatero y Lorrio 1999: 32-34).

Sea como fuere, pionero y tímido testimonio de ello serían el yacimiento de Los Quintanares de Escobosa de Calatañazor, fechado en el siglo VIII a.C., o aquellas cerámicas excisas a que tuvimos ocasión de referirnos páginas atrás y que datábamos en la centuria siguiente; todos ellos se adscribren hoy a la Fase Formativa de la Cultura Celtibérica o Protoceltibérico (Lorrio 1997: 260-261). Con posterioridad, durante la Edad del Hierro y desde el Celtibérico Antiguo, se asiste a la ocupación sistemática del Alto Duero, mostrando sus habitantes deudas en sus rasgos materiales, y claramente volvemos a insistir en sus cerámicas, respecto de las culturas de tradición de Campos de Urnas vecinas - del Ebro Medio, y particularmente navarro-riojanas, en el caso de los castros, y del Alto Jalón-Alto Tajo, y concretamente con la facies Riosalido, los poblados y necrópolis celtibéricos- (Romero y Misiego 1995b); dichos rasgos se mantendrán hasta iniciado el Celtibérico Pleno, durante lo que consideramos primera Edad del Hierro, entre un momento impreciso del siglo VII hasta una fecha en torno al 400 cal. a.C., como venía sugiriendo su cultura material y ha venido a precisar un estudio de las dataciones radiocarbónicas (Fig. 2, 1) (Romero 1999). $\mathrm{Y}$ si el proceso de deriva cultural antes comentado permite explicar el parentesco entre las cerámicas del Ebro Medio y las del Alto y 


\begin{tabular}{|c|c|c|c|}
\hline REFERENCIA & CALBP & CALBC 1s & CAL BC 2s \\
\hline Oncala Beta-244790 & $2930 \pm 40$ & $1208-1055(68.2 \%)$ & $1266-1008(95.4 \%)$ \\
\hline Oncala Beta-244789 & $2880 \pm 60$ & $\begin{array}{c}1189-1180(2.4 \%) \\
1156-1145(3.1 \%) \\
1130-974(59.7 \%) \\
954-943(3.0 \%)\end{array}$ & $1260-910(95.4 \%)$ \\
\hline Fuensauco Beta-47496 & $2700 \pm 90$ & $\begin{array}{c}974-956(4.9 \%) \\
941-793(63.3 \%)\end{array}$ & $\begin{array}{c}1122-748(91.5 \%) \\
688-666(1.4 \%) \\
642-590(2.1 \%)\end{array}$ \\
\hline Fuensauco Beta- 47495 & $2700 \pm 90$ & $\begin{array}{c}974-956(4.9 \%) \\
941-793(63.3 \%)\end{array}$ & $\begin{array}{c}1122-748(91.5 \%) \\
688-666(1.4 \%) \\
642-590(2.1 \%)\end{array}$ \\
\hline San Leonardo GrN- 19600 & $2490 \pm 15$ & $\begin{array}{c}754-739(8.9 \%) \\
688-685(1.7 \%) \\
668-664(2.3 \%) \\
648-608(24.8 \%) \\
600-548(30.6 \%)\end{array}$ & $\begin{array}{l}765-706(19.6 \%) \\
695-539(75.8 \%)\end{array}$ \\
\hline El Royo CSIC-418 & $2480 \pm 50$ & $\begin{array}{l}760(23.1 \%) 682 \\
670(45.1 \%) 522\end{array}$ & $\begin{array}{l}772479(84.9 \%) \\
470414(10.5 \%)\end{array}$ \\
\hline Cubo de la Sierra CSIC-881 & $2450 \pm 50$ & $\begin{array}{c}747-688(19.1 \%) \\
664-644(6.3 \%) \\
588-581(1.9 \%) \\
554-478(23.9 \%) \\
471-414(17.0 \%)\end{array}$ & $\begin{array}{l}761-682(23.0 \%) \\
671-406(72.4 \%)\end{array}$ \\
\hline Fuensauco Beta-52333 & $2430 \pm 70$ & $\begin{array}{c}746-688(16.8 \%) \\
664-646(5.1 \%) \\
552-405(46.4 \%)\end{array}$ & $766-397$ (95.4\%) \\
\hline Fuensauco Beta-47497 & $2410 \pm 100$ & $\begin{array}{c}750-687(14.5 \%) \\
666-642(5.4 \%) \\
592-396(48.3 \%)\end{array}$ & $\begin{array}{c}796-356(92.6 \%) \\
286-234(2.8 \%)\end{array}$ \\
\hline Cubo de la Sierra CSIC-475 & $2410 \pm 70$ & $\begin{array}{c}739-690(14.0 \%) \\
663-648(4.0 \%) \\
548-399(50.3 \%)\end{array}$ & $\begin{array}{l}764-680(19.8 \%) \\
673-390(75.6 \%)\end{array}$ \\
\hline Cubo de la Sierra CSIC-476 & $2380 \pm 50$ & $\begin{array}{c}536-530(2.0 \%) \\
523-393(66.2 \%)\end{array}$ & $\begin{array}{c}751-686(12.8 \%) \\
668-638(4.0 \%) \\
620-614(0.4 \%) \\
594-380(78.3 \%)\end{array}$ \\
\hline Cubo de la Sierra CSIC-527 & $2380 \pm 50$ & $\begin{array}{c}536-530(2.0 \%) \\
523-393(66.2 \%)\end{array}$ & $\begin{array}{c}751-686(12.8 \%) \\
668-638(4.0 \%) \\
594-380(78.3 \%)\end{array}$ \\
\hline Cubo de la Sierra CSIC-880 & $2380 \pm 50$ & $\begin{array}{r}536-530(2.0 \%) \\
523-393(66.2 \%)\end{array}$ & $\begin{array}{c}751-686(12.8 \%) \\
668-638(4.0 \%) \\
594-380(78.3 \%)\end{array}$ \\
\hline Fuensauco CSIC- 883 & $2380 \pm 50$ & $\begin{array}{c}536-530(2.0 \%) \\
523-393(66.2 \%)\end{array}$ & $\begin{array}{c}751-686(12.8 \%) \\
668-638(4.0 \%) \\
594-380(78.3 \%)\end{array}$ \\
\hline Fuensauco CSIC-907 & $2370 \pm 50$ & $520-390(68.2 \%)$ & $\begin{array}{l}750-686(11.0 \%) \\
667-640(3.2 \%) \\
594-366(81.1 \%)\end{array}$ \\
\hline Fuensauco CSIC-951 & $2360 \pm 30$ & $\begin{array}{c}502-500(1.2 \%) \\
487-462(16.4 \%) \\
450-440(5.2 \%) \\
418-390(45.3 \%)\end{array}$ & $522-382(95.4 \%)$ \\
\hline El Royo CSIC-536 & $2350 \pm 50$ & $512-382(68.2 \%)$ & $\begin{array}{c}746-688(7.2 \%) \\
665-646(1.7 \%) \\
554-354(81.6 \%) \\
290-232(4.6 \%)\end{array}$ \\
\hline Cubo de la Sierra CSIC-882 & $2340 \pm 70$ & $\begin{array}{c}705-695(1.8 \%) \\
539-358(59.5 \%) \\
282-257(5.1 \%) \\
244-235(1.7 \%)\end{array}$ & $\begin{array}{c}752-686(9.2 \%) \\
668-636(3.2 \%) \\
596-346(66.1 \%) \\
321-206(16.3 \%)\end{array}$ \\
\hline Fuensauco Beta-47498 & $2330 \pm 80$ & $\begin{array}{c}538-352(52.1 \%) \\
294-230(14.3 \%) \\
218-212(1.0 \%)\end{array}$ & $\begin{array}{c}752-686(8.6 \%) \\
668-633(3.4 \%) \\
596-200(82.6 \%)\end{array}$ \\
\hline Fuensauco CSIC- 477 & $2300 \pm 50$ & $\begin{array}{l}406-356(42.2 \%) \\
286-234(26.0 \%)\end{array}$ & $\begin{array}{c}508-438(5.8 \%) \\
420-336(48.0 \%) \\
330-203(41.6 \%)\end{array}$ \\
\hline Fuensauco Beta-47499 & $2290 \pm 80$ & $\begin{array}{l}411-336(27.7 \%) \\
331-203(40.5 \%)\end{array}$ & $\begin{array}{c}746-688(3.3 \%) \\
553-156(90.2 \%) \\
136-115(0.8 \%) \\
\end{array}$ \\
\hline El Royo CSIC-421 & $2270 \pm 50$ & $\begin{array}{l}396-354(31.1 \%) \\
291-231(37.1 \%)\end{array}$ & $404-203$ (95.4\%) \\
\hline Fuensauco CSIC- 478 & $2230 \pm 50$ & $\begin{array}{l}378-350(15.0 \%) \\
306-209(53.2 \%)\end{array}$ & $394-184$ (95.4\%) \\
\hline
\end{tabular}

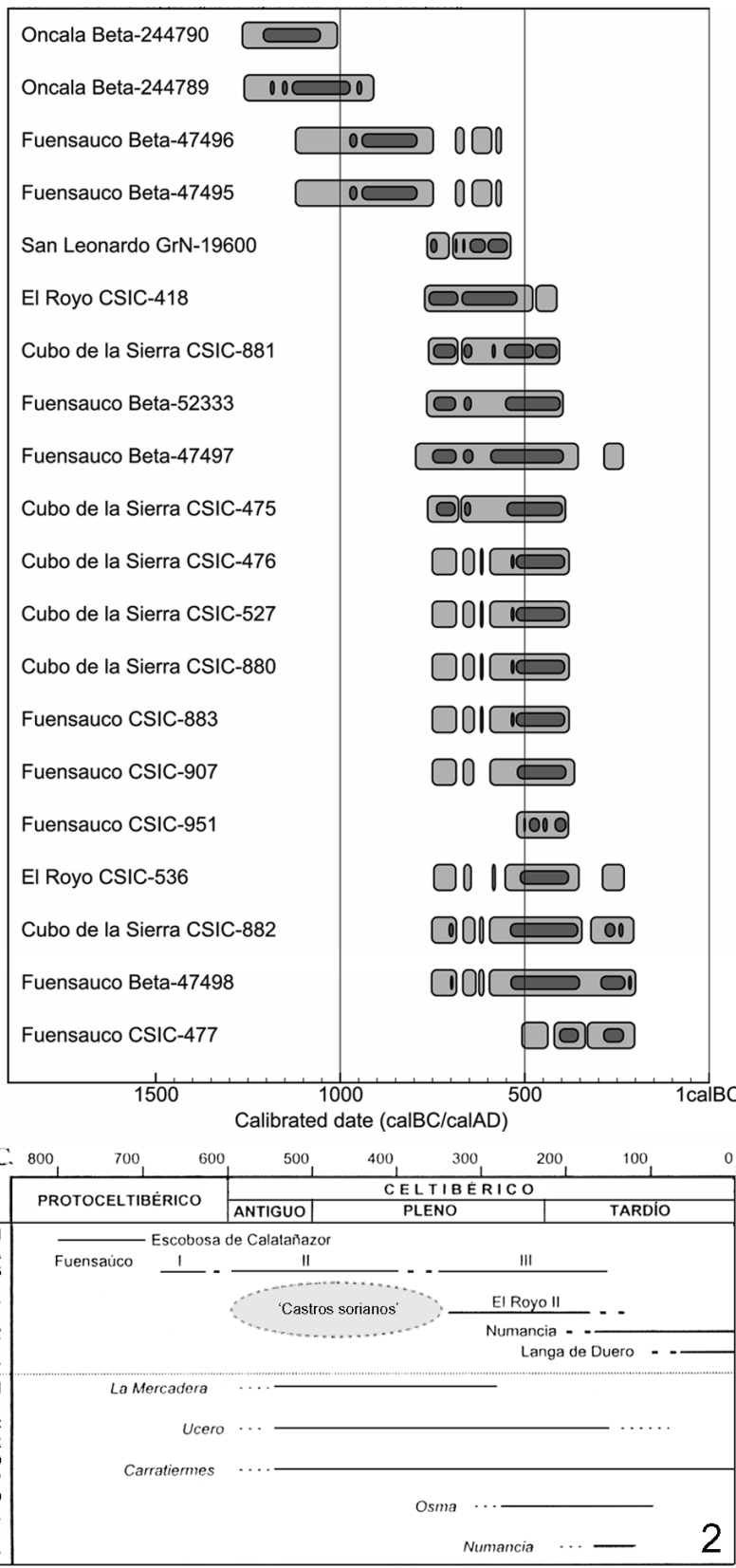

Figura 2.- 1, Fechas radiocarbónicas para la Edad del Hierro soriana y su representación gráfica (OxCal v4.1.7, Bronk Ramsey 2009); 2, Cuadro cronológico de los principales yacimientos de la cultura celtibérica en el Alto Duero (según Lorrio 1997).

Medio Duero, pudiera recurrirse igualmente a él para justificar cabañas circulares como las documentadas en la base de El Castillejo de Fuensaúco, que muestran grandes analogías con las que en el Duero Medio atestiguamos en la cultura del Soto (Romero 1992; Ramírez 1999), tratada en otro trabajo de este mismo volumen; ello, sin olvidar las particularidades que ofrecen al mismo tiempo una y otra zona del Valle del Duero, vendría a indicar que siguen manteniendo relaciones como las atestiguadas a lo largo del Bronce Medio-Final (Romero 1985; Delibes y Romero 1992; Romero y Jimeno 1993). 
En un momento en torno al 400 a.C., en el Celtibérico Pleno ya como queda dicho, tendría lugar el inicio de la que tradicionalmente venimos considerando segunda Edad del Hierro; el reemplazo de los molinos barquiformes o de vaivén por los circulares, la introducción del torno del alfarero y del horno oxidante y la consiguiente sustitución de las cerámicas a mano por las fabricadas a torno y decoradas con motivos pintados han venido considerándose, entre otros cambios en la cultura material, fósiles guía del inicio de dicho período, así como de la que sensu stricto se tenía hasta no hace mucho por etapa o cultura celtibérica. $\mathrm{Su}$ análisis, en cualquier caso, no es ya competencia del presente estudio.

\section{Sobre la ocupación del territorio y su materialización}

A lo largo de las páginas precedentes hemos venido refiriéndonos de forma constante a castros y poblados en tanto que entidades de población diferentes; y aun cuando pensamos que del texto se desprende lo que entendemos y queremos expresar con cada uno de esos términos, creemos llegado el momento de hacer alguna precisión al respecto, puesto que no podemos olvidar que tanto unos como otros son en definitiva poblados. Dado, por otro lado, que de cuanto acabamos de decir se desprende que los castros no son sino un tipo particular de poblados, parece lógico que nos centremos en su definición.

Por más que los topónimos con que son conocidos habitualmente este tipo de yacimientos - El Castillo, El Castillejo, El Castellar, o sus plurales correspondientes - vengan a coincidir en buena medida con una de las acepciones que de la palabra castro nos ofrece la Real Academia Española en su diccionario: "Altura donde hay vestigios de fortificaciones antiguas", no parece ésta la más adecuada a nuestro objetivo. Y no tanto ello por la ambigüedad que los términos "fortificación" y "antiguo" puedan introducir en la misma, cuanto por la incidencia que hace en el accidente geográfico, por más que como veremos este dato no sea nada desdeñable, y por el detrimento que ello significa para la idea que los prehistoriadores queremos resaltar: que se trata de un asentamiento humano; idea a la que cabría añadir que de carácter temporal ilimitado y no militar. Aspectos todos ellos a los que conviene curiosamente más una de las definiciones que el mismo diccionario ofrece para la palabra fortificación: "Obra o conjunto de obras con que se fortifica un pueblo o un sitio cualquiera".

Visto lo cual recurriremos a lo que sobre el particular han tenido a bien señalar dos voces autorizadas, pues es necesario reconocer que no siempre los especialistas se han visto en la necesidad de explicitar este aspecto en sus trabajos científicos. Sin que se trate propiamente de una definición, lo dicho al respecto por Ángel Esparza (1986: 385) es de una claridad meridiana: "Los criterios fundamentales para la clasificación de un yacimiento como castro son: emplazamiento defensivo, complementado por defensas artificiales que han de consistir como mínimo en una muralla, y materiales de la Edad del Hierro". Con clara intención definitoria Martín Almagro-Gorbea (1994: 15) se expresa, por su parte, así: "castro es un poblado situado en lugar de fácil defensa reforzada con murallas, muros externos cerrados y/o accidentes naturales, que defiende en su interior una pluralidad de viviendas de tipo familiar y que controla una unidad elemental de territorio, con una organización social escasamente compleja y jerarquizada".

Uno y otro, como se ve, parten de la idea básica antes anunciada de que nos encontramos frente a poblados e insisten en que a las buenas condiciones defensivas naturales suman sus habitantes cuando menos una artificial: la muralla. Incide el primero, además, en su caracterización cultural, puesto que si bien es cierto que se conocen asentamientos castreños durante el Calcolítico y a lo largo de la Edad del Bronce estos no constituyen la regla general en el seno de las respectivas culturas, en tanto que es durante la Edad del Hierro cuando se conocen las culturas castreñas por antonomasia, es decir aquellas que tienen en el castro su modelo de ocupación del territorio. El segundo insiste sobre todo en los aspectos económicos y sociales, aspectos que, en nuestro caso al menos, pudieran aplicarse igualmente a los restantes asentamientos contemplados, pues parece lógico asumir que dispusieran de 
un territorio de explotación propio y no han podido detectarse entre los poblados, ni entre sus habitantes, signos de jerarquización. En cualquier caso, hemos de tener en cuenta que pocos son los datos con que contamos relativos a las fases iniciales de tales lugares de habitación, debiendo señalarse, de forma general, la ausencia de jerarquización interna, aunque la falta de excavaciones en extensión dificulta la posibilidad de obtener mayor información sobre el particular. No obstante, si nos atenemos a las noticias procedentes de los cementerios parece que, desde sus fases iniciales, como tendremos ocasión de comentar más adelante, se evidencian indicios de jerarquización social, apareciendo el armamento como un signo exterior de prestigio; y aunque no existe la posibilidad, con los datos que poseemos, de determinar qué proporción de sepulturas adscritas a este momento estarían provistas de armas, puede aventurarse que el grupo enterrado con ajuares militares no debió ser muy numeroso, correspondiendo posiblemente al sector más privilegiado de la sociedad, debiendo de interpretarse estas armas como elementos definidores del estatus de su poseedor.

Pues bien, hechas estas consideraciones y vistas con anterioridad las diferentes preferencias geográficas mostradas por los habitantes de los castros y de los poblados, que en contraposición podríamos calificar de abiertos y mejor llamar celtibéricos a la vista de lo dicho en el apartado precedente, nos detendremos en este epígrafe en analizar sus patrones de asentamiento en lo que a los emplazamientos se refiere y en ver cómo se materializan dichas ocupaciones a través de las arquitecturas defensiva y doméstica.

\subsection{Los castros de la serranía}

Conocidos desde bien tempranamente (Taracena 1929: 3-27), los castros sorianos han seguido siendo objeto de atención, aunque de forma intermitente y diversa, en años sucesivos y hasta nuestros días, como revelan numerosos trabajos y, en última instancia, un amplio estudio monográfico (Romero 1991) a ellos dedicados.

Situados estratégicamente en los contrafuertes más importantes del Sistema Ibérico, en emplazamientos con óptimas condiciones defensivas naturales, dominan el curso de los ríos principales, presiden o jalonan sus valles y vigilan los accesos y vías de comunicación naturales; en ningún caso los lugares en que se asientan, cuya altitud media es de $1.250 \mathrm{~m}$, constituyen la elevación máxima del entorno. No puede decirse que sus emplazamientos respondan a un modelo característico (Fig. 3), pues se atestiguan desde el tipo "en espolón" -El Pico de Cabrejas del Pinar, Alto del Arenal de San Leonardo- y su variante "en espigón fluvial" - Castro del Zarranzano de Cubo de la Sierra (Fig. 3, 1) - al de "en escarpe" o "farallón" - El Castillejo de Langosto-, pasando por distintas variantes del "en colina" o "acrópolis" - Los Castillejos de Castifrío de la Sierra (Fig. 3, 2), Alto de la Cruz de Gallinero, Los Castillejos de El Espino o El Castillejo de Hinojosa de la Sierra - o el "en ladera" —El Castillo de las Espinillas de Valdeavellano de Tera, El Castillo de El Royo (Fig. 3, 3) y Los Castillejos de Gallinero (Fig. 3, 4) - (Romero 1991: 185-197).

Todos los castros son de extensión reducida, pues su superficie rara vez supera la hectárea, y tienen un sólo recinto, que cierra siempre una muralla; ésta, por lo general la principal y única defensa, según el tipo de emplazamiento, y buscando sin duda amortizar el máximo de tiempo y esfuerzo en su erección, los circunda en su totalidad - Los Castillejos de Gallinero- y de ser viable, aprovechando los afloramientos rocosos naturales - Hinojosa de la Sierra-, se apoya en cantiles o crestones calcáreos - El Castillejo de Taniñe - o hace inaccesible el flanco más vulnerable - Castro del Zarranzano- , de donde lo variado de sus plantas. Dichas obras se construyeron con piedras de mediano y pequeño tamaño, careadas naturalmente y encontradas en seco; su estructura es simple: entre dos paramentos de mampostería, verticales - Castilfrío de la Sierra - o en talud - Valdeavellano de Tera-, se disponen arbitrariamente materiales más pequeños y menos regulares. Su anchura oscila entre los dos metros y medio y los seis y medio, y hay que suponer que en origen alcanzarían, cuando menos, los cuatro metros de altura. Difícil resulta, dado el estado de derrumbe actual de sus murallas, la localización de las puertas de acceso 
al interior de estos castros, y si en algún caso se han identificado con simples interrupciones en el trazado de aquellas en otros parecen ubicarse entre uno de sus extremos y el accidente natural al que con frecuencia vienen a morir (Romero 1991: 197-209). Otro tanto ocurre en relación con la existencia de posibles torres, pues apenas si puede basarse en otro dato que el aumento del volumen de los derrumbes de las murallas en algún punto de su trazado; de ahí la necesidad de destacar los cinco torreones semicirculares adosados al exterior de la de El Castillo de las Espinillas de Valdeavellano de Tera (Fig. 4, 1) (Ruiz Zapatero 1977).

Cuatro de estos últimos se sitúan en el castro citado en su flanco más vulnerable, el septentrional en este caso, y otro tanto cabe decir de los frisos de piedras hincadas y fosos que se levantaron o excavaron en algunos otros, razón por la cual no siempre acompañan a la muralla en todo su recorrido. La anchura de las barreras de piedras hincadas varía de unos castros a otros, aunque puede decirse que oscila entre cinco y veinte metros, y es normal que entre ellas y la muralla medie un espacio, de anchura igualmente variable, vacío: la berma (Romero 2003). En ocasiones, sin embargo, se sitúa aquí un foso - defensa complementaria, cuya existencia niega algún autor (Bachiller 2008), con la que cuentan cuatro castros, la mitad de los que tienen piedras hincadas-, tal y como ocurre en Los Castillejos de Gallinero y El Castillejo de Castilfrío de la Sierra; en Hinojosa, por el contrario, el foso constituye la defensa más externa, ubicándose las piedras hincadas, por lo tanto, en la berma (Fig. 4, 2). Más compleja es la disposición que ofrecen en el Alto del Arenal, pues las piedras hincadas debieron de cubrir una franja de unos veinte metros de anchura intercalada entre dos fosos (Romero 1991: 209-210).

Parece lógico que todos estos sistemas defensivos se construyeran a un tiempo y que, por tanto, ni su adición ni la diferente ordenación de los mismos tengan valor cronológico alguno, máxime si pensamos que debieron estar
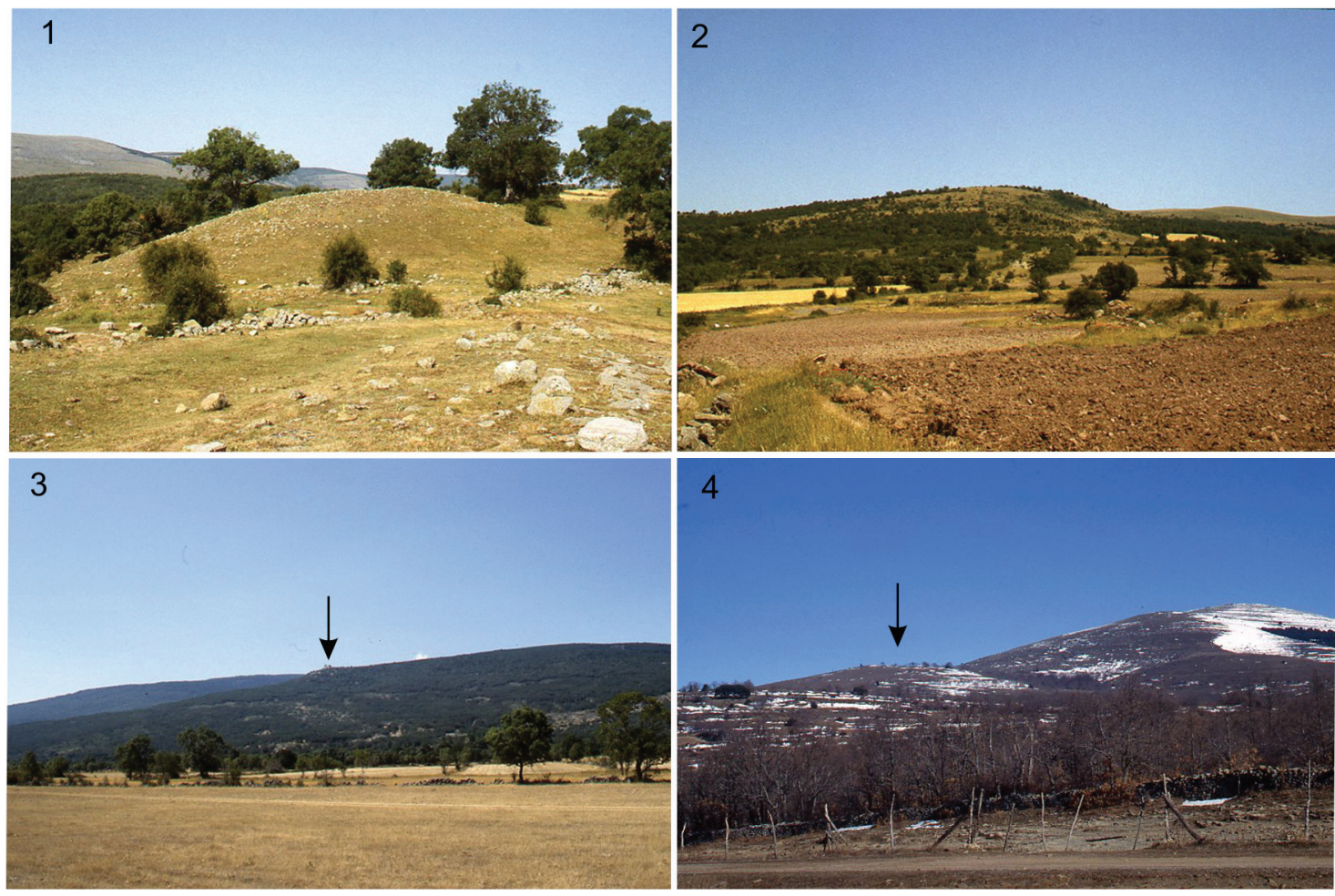

Figura 3.- Vistas de la muralla del castro del Zarranzano (1), de Los Castillejos de Castilfrío de la Sierra (2), de El Castillo de El Royo (3) y de Los Castillejos de Gallinero (4). 
condicionados por el mismo emplazamiento; si pudiera tenerlo, por el contrario, tal y como ha señalado Ángel Esparza (1980: 81-82), la complejidad defensiva derivada de su acumulación que, característica de la cultura castreña del Noroeste, es esgrimida como signo de modernidad. En nuestro caso, la sencillez del trazado y estructura de las murallas y la simplicidad de sus accesos han venido valorándose como índice de antigüedad y otro tanto se señalaba, hasta su detección en Els Vilars de Arbeca, en Lérida, de las piedras hincadas, hasta el punto de haberse llegado a sugerir que hubiera sido precisamente aquí, en el Alto Duero, donde, aunque tardíamente, se gestara la idea del castro fortificado, que tan amplia aceptación habría de tener después, a lo largo de la Edad del
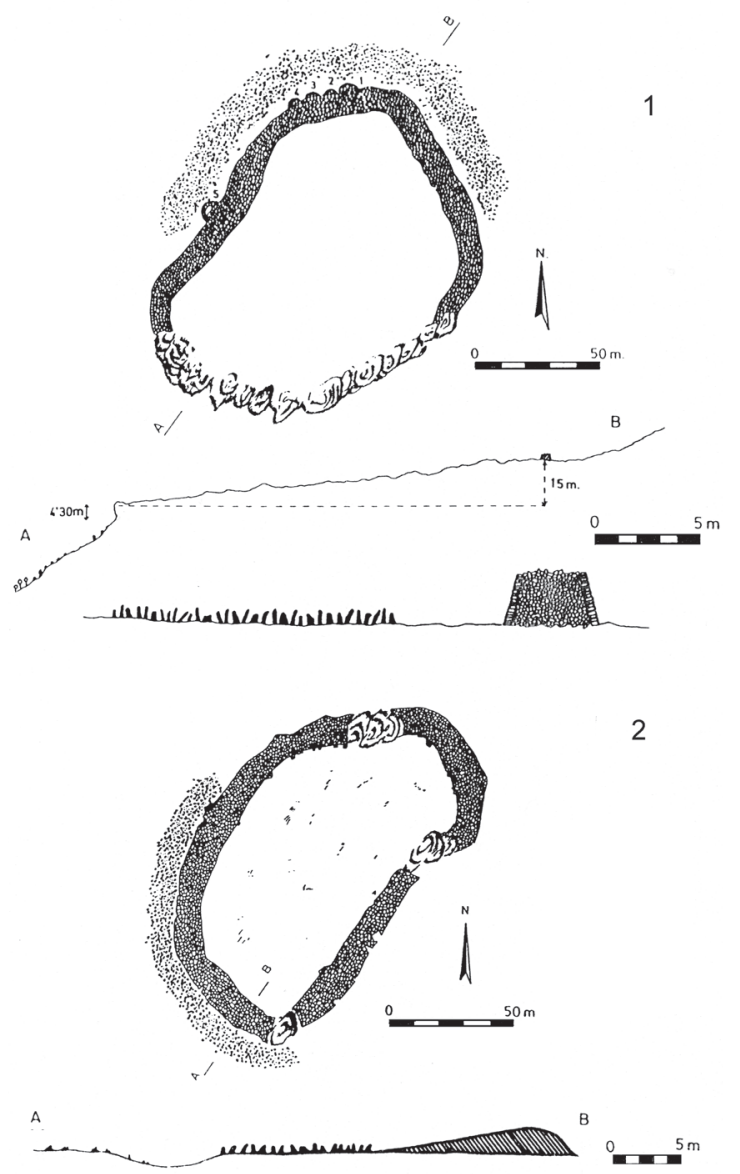

Figura 4.- Plantas y perfiles de las defensas de El Castillo de las Espinillas de Valdeavellano de Tera (1) y de El Castillejo de Hinojosa de la Sierra (2) (según Taracena 1929; la ubicación de los torreones del primero —núms. 1-5—, según Ruiz Zapatero 1977).
Hierro, en la Meseta primero y en el Noroeste después.

La procedencia de torres y torreones en los castros de la Edad del Hierro de la Meseta es discutida, inclinándose el descubridor de los de el de Valdeavellano de Tera por su origen indoeuropeo, así como por su transmisión, desde tierras sorianas y por el Sistema Central, al territorio vettón, donde documenta los paralelos más próximos. Por lo que a las piedras hincadas se refiere, y desde una perspectiva igualmente difusionista, se ha venido señalando su origen en las estacadas centroeuropeas del Hallstatt $\mathrm{C}$, y el hecho de que en el yacimiento francés de Pech Maho fueran ya de piedra sugería que estas se hubieran impuesto previamente a su introducción en nuestra península, en la que, por tanto y como vendría a evidenciar además ahora el yacimiento leridano citado, habrían sido de dicho material desde un principio; desde aquél, en el que se fechan a partir de la segunda mitad del siglo VII a.C., habrían llegado al territorio que estudiamos, desde donde a su vez, y nuevamente a través del Sistema Central como permitirían confirmar los ejemplos de la provincia de Guadalajara, se habrían difundido hacia occidente primero y más tarde al Noroeste. Sin embargo, vista, por un lado, la problemática cronología que plantean las piedras hincadas peninsulares (Esparza 1986: 358-362) y, por otro, la moderna datación, siglo IV a.C., de las del pretendido hito francés (Gailledrat y Moret 2003: 127-129), Pierre Moret (1996: 129-130 y 222-226) ha cuestionado que la Europa central hallstáttica sea el único origen posible para tal sistema defensivo y contempla la alternativa de un hogar original occidental; es más, Ángel Esparza (2003: 169-171) ha llamado la atención sobre la falta de relación entre los diferentes grupos peninsulares y llegado a sugerir, en última instancia, un origen independiente para los mismos.

Tradicionalmente también se ha venido sosteniendo que tales barreras constituirían un sistema defensivo eficaz contra los ataques de la caballería, interpretación con la que discrepan hoy la práctica totalidad de los investigadores, quienes, con sólidos y variados argumentos, entienden que su auténtica finalidad sería dificultar los ataques de la infantería; máxime ello cuando, para las fechas en las que nos movemos, 
difícilmente puede hablarse de la existencia de una auténtica caballería en la Península Ibérica $\mathrm{y}$, mucho menos, en las tierras del interior (Moret 1996: 226-227; Quesada 2003: 92-95). Así, en el caso de las más orientales al menos, parecen estar ya en desuso con anterioridad al apogeo de las elites ecuestres. En efecto, en Els Vilars el campo de piedras hincadas fue paulatinamente cubierto a lo largo de la fase ibérica antigua, o Vilars II, estando totalmente fuera de servicio al excavarse el foso en Vilars III (G.I.P. 2003: 243250), lo que viene a decirnos, teniendo en cuenta que se levantó durante Vilars I, que se mantuvo efectivo por espacio de en torno a un siglo, entre el 650 y el 550 a.C. (Alonso, Junyent y López 2010: 14-15 y 20-23). En Soria, el deterioro que ofrecen tanto en El Pico de Cabrejas del Pinar como en el Alto del Arenal de San Leonardo, yacimientos ambos que continúan su vida en la segunda Edad del Hierro, ha llevado a pensar que ya estuvieran fuera de uso en dicha fase, y abundaría en ello el hecho de que ninguno de los numerosos poblados que se fundan del siglo IV en adelante cuente con tales frisos; otro tanto ocurriría, quizás, con las de Castilviejo de Guijosa, en Guadalajara, de las que se sospechó que no fueran contemporáneas de la muralla que ha llegado a nosotros sino de otra de época anterior, que supuestamente habría quedado fosilizada por ésta, aunque el hallazgo en el cercano castro de Hocincavero (Anguita) de una barrera de piedras hincadas — atravesada por un pasillo como en Guijosa y Cabrejas del Pinar-, en un contexto en el predominan abrumadoramente las cerámicas torneadas, deje abierto el posible uso, ya de forma residual, durante el Segundo Hierro (Romero 2003: 200-206). Bien elocuentes resultan, por otro lado y en este mismo sentido, los ajuares de las sepulturas celtibéricas, pues si bien es cierto que durante el Celtibérico Antiguo se constatan ya tumbas militares y se señala la presencia de arreos de caballo en las de Carratiermes, no lo es menos que estos adquieren carta de naturaleza durante el Celtibérico Pleno, como atestigua La Mercadera, y se mantienen en el Celtibérico Tardío, momento este último para el que otros documentos, más amplios y diversos, nos informan sobre la importancia de la caballería (Lorrio 1997: 235-237 y 280-282).

En otro orden de cosas ya, el hecho de que tras excavar en varios de estos castros no llegara Blas Taracena a detectar estructura alguna le llevó a suponer que los más antiguos contaran con simples cabañas como viviendas y que las construcciones de mampostería habrían comenzado a emplearse en un momento avanzado del desarrollo de la cultura (Taracena 1941: 14); dos de los yacimientos a que se refiriera dicho autor han deparado en las excavaciones modernas habitaciones y estructuras de piedra - el Castro del Zarranzano y El Castillo de El Royo- y se ha llamado la atención, en este mismo sentido, a raíz de las observaciones realizadas en algún otro caso, de ahí que parezca lógico presumir - máxime si se valora que todos ellos cuentan con murallas y, en ocasiones, con otros sistemas defensivos levantados con piedra, haciendo gala de una tradición constructiva con base en este material - que todos ellos tuvieran casas de mampostería.

Parece lógico recordar también en este momento el hallazgo, en el nivel inferior del castro de El Royo, de una estructura circular de piedra de reducido tamaño, pues tiene tan sólo metro y medio de diámetro, que por su asociación a moldes de fundición y escorias de hierro ha sido considerada un horno metalúrgico (Eiroa 1981), aunque la estructura no se corresponda con las habituales de hornos contemporáneos de otras regiones mejor conocidas (Lorrio et al. 1999: 168). Dichos moldes de fundición, al igual que otros recuperados en el yacimiento vallisoletano de El Soto de Medinilla o en el alicantino de La Peña Negra de Crevillente (Delibes et al. 1995: 70), son de arcilla y los objetos de bronce que con ellos se fabricaban - escoplos, varillas, empuñaduras - denuncian una tipología antigua, de en torno al tránsito Bronce Final-Edad del Hierro, que contrasta vivamente con la de los objetos habitualmente recuperados en los castros, de cronología más bien tardía, pues, en efecto, estos remiten en su mayor parte al siglo $\mathrm{V}$ a.C. con exclusividad. Tales objetos, en número muy reducido por lo demás, se limitan al puente romboidal de una fíbula de doble resorte, el eje de una fíbula de espirales, dos ejemplares de fíbula de pie vuelto con botón terminal, varios fragmentos de agujas que pudieran pertenecer a fíbulas también y dos fragmentos de brazaletes del tipo oval, abierto y de sección rectangular (Romero 1991: 310322, fig. 77), amén de otras pocas piezas, a las que nos referiremos después, recuperadas en el 
Castro del Zarranzano. Puramente testimoniales puede decirse que son los vestigios de hierro, de ahí que sea preciso citar el único objeto reconocido: un fragmento de hoja de cuchillo procedente del castro de Castilfrío de la Sierra.

Mucho mejor conocida que la metalurgia nos es la vajilla utilizada por los habitantes de los castros. Se documentan entre sus cerámicas (Fig. 5, 2), siempre hechas a mano, casi una treintena de formas (Romero 1991: figs. 73-74), de entre las que destacaremos en primer lugar los cuencos y otros vasos de pequeño tamaño, caso de los ejemplares carenados, de superficies cuidadas y en muchas ocasiones bruñidas; junto a ellos se documentan otros, de tamaño medio o grande y apariencia ordinaria, de perfiles ovoides, globulares o bitroncocónicos, entre los que cabe citar aquellos con cuellos perfectamente diferenciados. Es notoria, por otro lado, la pobreza decorativa de estas cerámicas, ya que se reduce, en los más de los casos, a impresiones digitales o ungulaciones en los bordes, o sobre cordones y baquetones que delimitan diferentes partes de su cuerpo, y a un número muy reducido de temas incisos (Romero 1991: fig. 75); de ahí que destaquen, pese a lo reducido de su número, los finos ejemplares grafitados o pintados. En general, dichas piezas se relacionan con las de otros grupos de la primera Edad del Hierro vecinos, pero muy particularmente, pues no hay que olvidar sus numerosos paralelos formales (Romero 1984b: 27), con las de las estaciones navarro-riojanas de tradición de Campos de Urnas; analogías todas ellas que permiten datarlas desde mediados del siglo VII a comienzos del IV a.C.

Como puede apreciarse, la cronología proporcionada por las cerámicas amplía considerablemente la ofrecida por los bronces, estando más acorde con la que desde un principio se viene asignando a la cultura de los castros sorianos, de entre los siglos VI y IV a.C. Dos dataciones radiocarbónicas obtenidas para El Castillo de El Royo (Fig. 2, 1), que a decir de su excavador vendrían a fechar el inicio y fin de su ocupación castreña (Eiroa 1984-1985: 198), son, de acuerdo con el test del chi-cuadrado, estadísticamente semejantes, lo que ha permitido obtener una nueva datación a partir de su media ponderada; ésta, calibrada a dos sigmas presenta para el intervalo 550-394 cal. a.C. una proba- bilidad superior al 75 por 100 , lo que permite fijar dicha ocupación castreña entre mediados del siglo VI e inicios del IV cal. a.C. (Romero 1999: 144-146). Una nueva datación C-14, de la que por desgracia desconocemos el contexto arqueológico, ha sido facilitada por el Alto del Arenal; calibrada igualmente a dos sigmas, y teniendo en cuenta su confianza máxima de probabilidad, se sitúa entre la primera mitad del siglo VIII y el último cuarto del VI cal. a.C. (Romero 1999: 149-150), cronología un tanto alta si se compara con la de El Royo citada y, más aún, con la del Castro del Zarranzano que, como veremos seguidamente, se centra en el siglo V cal. a.C.

Finalmente, por ser hoy el mejor conocido, dedicaremos alguna atención al Castro del
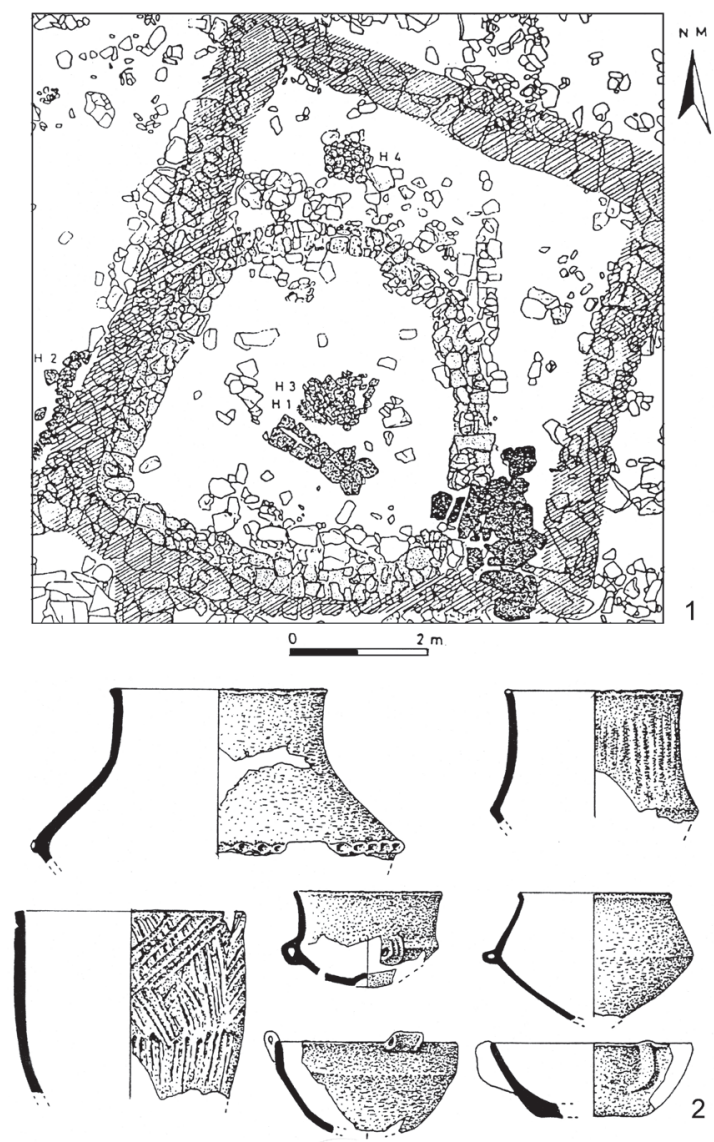

Figura 5.- Castro del Zarranzano: planta de las viviendas superpuestas (1) (H1 a 4, hogares; en trama más oscura, el acceso a la vivienda circular) (según Romero 1989) y cerámicas a ellas asociadas (2), a diferentes escalas (según Romero 1991). 
Zarranzano (Romero 1991: 70-75). Constituye un magnífico ejemplo de emplazamiento en espigón fluvial, pues se sitúa, sobre un pequeño promontorio de $1.080 \mathrm{~m}$ de altitud, en la horquilla que forman en su confluencia los ríos Tera y Zarranzano; presenta, en virtud de ello, planta triangular y su superficie, escalonada en dos terrazas, apenas si alcanza una hectárea de extensión. Dado que dos de sus flancos quedan protegidos por los mencionados cursos fluviales, se erigió para la defensa del tercero, que se abre a las tierras llanas del valle del Tera, una muralla de mampostería en seco, que tenía una anchura de cinco metros y medio en su elevación y de algo más en su cepa, cuyos derrumbes alcanzan hoy más de dos metros de altura (Fig. $3,1)$. El camino actual, que por el sur y a media ladera permite el acceso directo a la plataforma inferior, debió de constituir asimismo en su día la vía de entrada a su interior. Si las antiguas excavaciones llevaron a suponer que sólo la terraza superior hubiera estado ocupada y que las viviendas hubiesen sido simples cabañas construidas con materiales perecederos, las más modernas, que han afectado a diferentes sectores del castro, han permitido comprobar que todo él estuvo habitado y que las construcciones ofrecen siempre, cuando menos, cimientos de piedra (Romero 1991: 129-183).

Dichos trabajos, centrados en lo que conocemos como Sector II (Romero 1989: 50-53), permitieron comprobar cómo, una vez regularizado el terreno, se construyó una primera vivienda, de planta prácticamente cuadrada, cuyos muros cierran una superficie aproximada de treinta y seis metros cuadrados; éstos, que miden entre setenta y noventa centímetros de ancho y conservaban entre dos y cinco hiladas, se construyeron con bloques de conglomerado de mediano y gran tamaño acuñados con piedras rodadas más pequeñas (Fig. 5,1 ). En su interior se dispuso el hogar, y junto a él un vasar, formado por dos alineaciones de piedras rodadas de superficie plana; es posible que el grupo de cantos localizado junto a ellos hubiera servido para acuñar un poste que sustentara la techumbre. Superpuesta a la vivienda descrita, y apoyada en el ángulo suroccidental de la misma, apareció una segunda, de planta redondeada en esta ocasión, cuyo diámetro interno es de cinco metros y su superficie de unos vein- te metros cuadrados (Fig. 5, 1). Sus muros, de medio metro de ancho, apenas si conservaban esta misma altura y fueron construidos a base de piedras rodadas de mediano tamaño encontradas en seco. La entrada a la misma, orientada al Sureste, venía indicada por un enlosado; en su interior, y aproximadamente en el centro, apareció un hogar, de características análogas al de la vivienda infrayacente.

Las mencionadas excavaciones han proporcionado abundantísimos materiales cerámicos (Fig. 5, 2), hasta el punto de poder señalarse que la tabla de formas cerámicas de los castros sorianos es deudora de ellas, por lo que no merece la pena volver a insistir sobre el particular; de la misma manera algunos bronces, entre los que pueden citarse: botones semiesféricos, pasadores o restos de agujas, posiblemente de fíbulas, y brazaletes de sección circular, y extremos ensanchados en un caso. Y si el estudio de dichos materiales vino a indicar en su momento que el castro debió estar habitado en esencia a lo largo del siglo V a.C. (Romero 1991: 179-183), otro tanto indican las dataciones absolutas; en efecto, la media combinada de las seis fechas C-14 aportadas por el mismo, que entendemos refleja desde el punto de vista del radiocarbono su vida, ofrece, calibrada y para los rangos de confianza a una y dos sigmas, respectivamente, los intervalos cronológicos cal. BC 482-398 y 512-397, lo que permite contemplar que el Castro del Zarranzano estuvo ocupado poco más de una centuria, entre finales del siglo VI e inicios del IV cal. a.C. (Romero 1999: 146-149).

Dicha cronología, al igual que la del castro de El Royo antes comentada, viene a situar el final de la cultura castreña soriana al filo del 400 cal. a.C., momento en el que muchos de estos yacimientos fueron abandonados, y es corroborada por una tercera datación del castro citado que fecha la ocupación del mismo durante la segunda Edad del Hierro en los siglos IV-III cal. a.C. (Romero 1999: 146).

\subsection{Los poblados celtibéricos}

Los poblados, a los que llamaremos decididamente ya celtibéricos según lo dicho, fueron documentados inicialmente en la Tierra de Al- 
mazán (Revilla 1985; Revilla y Jimeno 198687) y su nómina ha venido ampliándose, hasta situarse en torno a la decena, al amparo de las prospecciones que, intensificadas en las últimas décadas del siglo XX con vistas a la elaboración del Inventario Arqueológico provincial, han servido paralelamente para la revisión y puesta al día de la antigua Carta Arqueológica (Taracena 1941). Hasta le fecha no disponemos de ningún trabajo de conjunto sobre los mismos, aunque los estudios de síntesis más recientes vienen haciéndose eco de ellos (Romero y Ruiz Zapatero 1992: 112-113; Romero y Jimeno 1993: 206-209; Romero y Misiego 1995b: 72-73; Lorrio 1997: 267-268).

Dispersos, como queda reiteradamente dicho, por las tierras llanas del centro y sur de la provincia de Soria, se sitúan en cerros aislados o sobre espolones o plataformas de otros cerros, cuyas cotas varían de los 900 a los 1.150 $\mathrm{m}$ de altitud, aunque sin superar nunca los cincuenta metros de desnivel respecto de los terrenos circundantes, lo cual les procura una cierta protección natural. Se asientan pues sobre emplazamientos elevados, aunque en ningún caso inaccesibles, con amplia visibilidad sobre el entorno y próximos a los cursos de agua; todos esos rasgos les confieren un carácter estratégico, del que únicamente se ve privado La Estevilla de Torremediana que, aunque ubicado en un territorio relativamente accidentado, no destaca en altura por encima de su entorno.

Aunque se desconoce cualquier tipo de construcción defensiva asociada a estos poblados, los trabajos de prospección llevados a cabo en el sector soriano que ahora nos ocupa han permitido detectar la presencia de murallas en algunos casos, lo que podría llevar a matizar la dicotomía señalada con respecto a la cultura castreña de la serranía norte y aun, como se ha señalado en alguna ocasión (Pascual 1991: 263) -opinión que no compartimos-, a extender el límite meridional de ésta hasta las campiñas del Duero. Bien es cierto que en el de Alepud, en Morón de Almazán, los restos de la posible muralla pudieran ser posteriores pues el lugar, como denuncia la presencia en él de cerámicas a torno, continuó habitado durante el Celtibérico Pleno (Revilla 1985: 204-212 y 329). Otro tanto cabe decir de Los Castillejos, en Cubo de la Solana, pues si su origen puede retrotraerse hasta la primera Edad del Hierro - lo que llevado a contemplarlo, junto con los de Cuevas de Soria y Nódalo, a los que nos referiremos a continuación, como uno de los ejemplos más meridionales de la cultura castreña soriana (Pascual 1991: 92 y 263)—, la ocupación se extendió hasta un momento avanzado de la etapa celtibérica (Borobio 1985: 6986), lo que dificulta de nuevo la datación de la muralla; es más -y de ahí, en parte, nuestra reticencia a incluirlo entre los castros de la serranía-, recientemente se ha identificado, a algo más de un kilómetro, la necrópolis perteneciente a este asentamiento, fechada entre los siglos VI y II a.C. (Tabernero, Sanz y Benito 2010: 395-398). También en la Zona Centro se han identificado asentamientos provistos de murallas, como El Castro, en Cuevas de Soria, donde se constata asimismo la presencia de materiales cerámicos a mano y a torno (Pascual 1991: 91-96), o El Castillejo, en Nódalo, yacimiento en cuyo interior no pudo recuperarse material arqueológico alguno, aunque si pudieron recogerse un par de fragmentos de cerámica muy rodada, al parecer hecha a mano, en sus inmediaciones (Pascual 1991: 141).

La ausencia de obras defensivas en la mayoría de los casos dificulta la evaluación de sus extensiones, si bien estas pudieran oscilar entre la hectárea de Cubo de la Solana (Tabernero, Sanz y Benito 2010: 398), las aproximadamente dos de La Buitrera de Rebollo y las cinco o seis de La Corona de Almazán (Jimeno y Arlegui 1995: 104).

Las prospecciones de las que se deriva su descubrimiento han permitido recuperar en ellos cerámicas a mano pobremente decoradas con ungulaciones o impresiones digitales en bordes o carenas, en el caso de las más toscas, y rara vez con pintura o grafitado en los vasos de menor tamaño y factura más cuidada; dichas producciones, que conocemos mucho mejor a partir de las excavaciones de El Castillejo de Fuensaúco (Fig. 7,1 ), son análogas formal y decorativamente en muchos casos a las de los castros, aunque se relacionan igualmente, y mejor que las de aquellos, con las que al sur del Sistema Central, y en la provincia de Guadalajara, comparecen en los poblados del grupo Riosalido (Barroso 1993: fig. 6). 

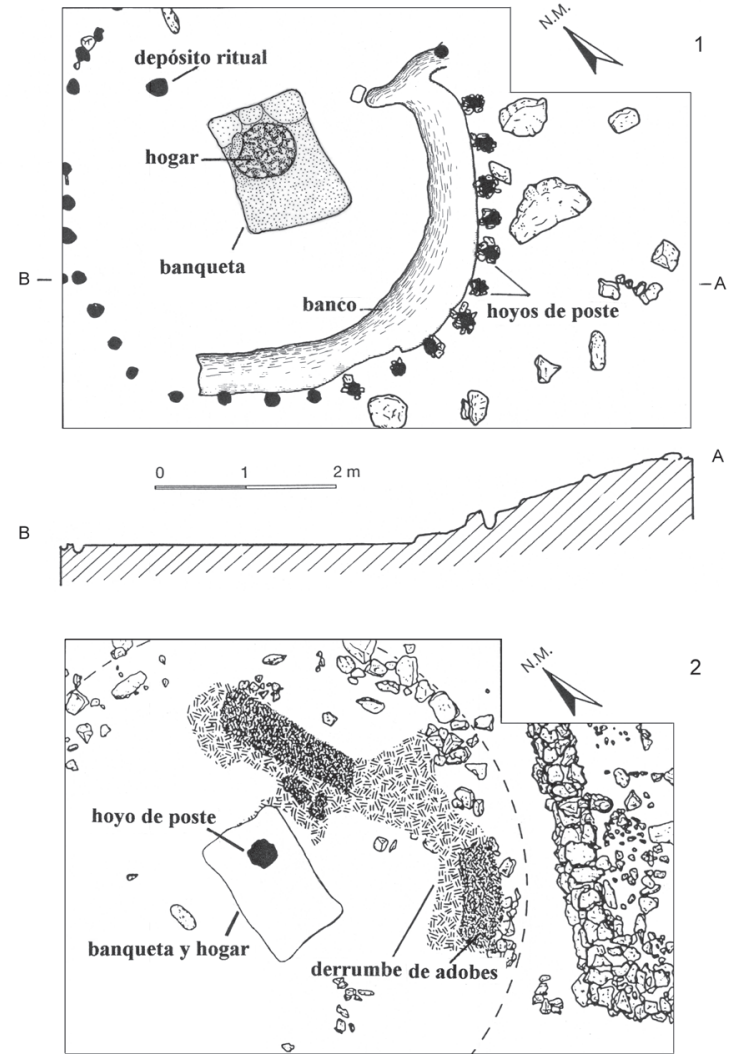

Figura 6.- El Castillejo de Fuensaúco, Sector II: 1, planta y perfil de la cabaña circular de la fase inicial; 2, planta de las viviendas rectangular y circular - en línea discontinua - del segundo nivel de ocupación del poblado (según Romero y Misiego 1992 y 1995a).

Hasta hoy sólo se ha excavado El Castillejo de Fuensaúco, asentado sobre la cima y ladera septentrional, aterrazada, de un pequeño cerro que, inmediato a la localidad citada, alcanza los $1.129 \mathrm{~m}$ de altitud (Taracena 1929: 20-23; Romero 1991: 377-404; Romero y Misiego 1992 y 1995a). Las intervenciones más recientes han afectado a la terraza inmediatamente inferior a la cumbre del cerro, Sector I, y, sobre todo, a la que mucho más amplia, y conocida como Sector II, se abre prácticamente a sus pies; sector este último que ha procurado una dilatada secuencia estratigráfica que permite suponer que el poblado se mantuviera en pie ininterrumpidamente a lo largo de unos quinientos años.

En la base de dicha secuencia se exhumó una vivienda de planta circular, de unos seis metros de diámetro, cuyo perímetro dibujan cerca de una treintena de hoyos de poste, que en el caso de estar excavados en la roca se acuñan con piedras (Fig. 6, 1); delante de ellos por el sur, y a un escalón asimismo excavado en la roca, se adosa un banco corrido, que estuvo revocado, cuya interrupción por el este obliga a pensar que la entrada debió orientarse en dicha dirección; hacia el centro de la cabaña se localizó una banqueta rectangular de adobes, también revocada, sobre cuya superficie se situó un hogar circular, que quedaba protegido por otros adobes de cara a la puerta; finalmente, enterrados en un hoyo, debajo del piso de arcilla fuertemente apisonada, aparecieron restos de dos pequeños ovicaprinos, que sus excavadores han relacionado con un sacrificio fundacional (Romero y Misiego 1995a: 130-134, fig. 2). En el Sector I pudo apreciarse asimismo un escalón excavado en la roca madre, que describía un arco de circunferencia de poco más de seis metros de diámetro; dicho entalle se ha interpretado como un fondo de cabaña, máxime cuando en el interior del círculo, y aproximadamente en su centro, apareció un hogar circular formado por un lecho de cantos rodados y una solera de arcilla rojiza endurecida por el fuego (Romero y Misiego 1992: 311, fig. 2). Se asocian a esta primera ocupación variados cuencos lisos y vasos bitroncocónicos u ovoides, decorados a veces con ungulaciones o digitaciones, de gran tamaño (Fig. 7, 1); con ella ha venido vinculándose un fragmento de cerámica excisa, recuperado en prospección, del tipo de las que según comentamos anteriormente se adscriben hoy en este ámbito al Protoceltibérico.

Volviendo al Sector II recordaremos cómo a la ocupación mencionada se superpone otra a la que corresponden sendas viviendas de plantas circular y rectangular, respectivamente (fig. 6, 2). La primera, construida en buena medida sobre la anteriormente descrita, apareció muy desmantelada, aunque no lo suficiente como para no poder apreciar que sus cimientos, de piedra ahora, describen un arco de casi seis metros de diámetro y que sus paredes, derrumbadas hacia el interior, se alzaron con adobes. En su centro se localizó, una vez más, una placa rectangular que, construida sobre un lecho de fragmentos cerámicos y formada por dos capas de arcilla fuertemente compactada, se empleó para en- 

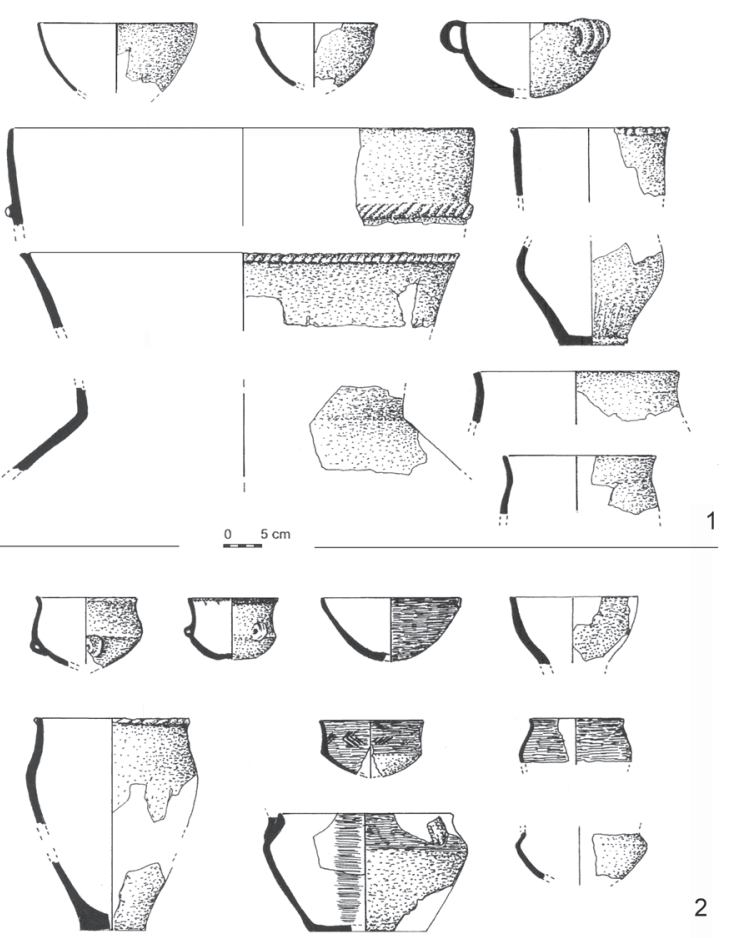

2

Figura 7.- El Castillejo de Fuensaúco: Cerámicas representativas de las ocupaciones inicial (1) y plena (2) del poblado durante el Primer Hierro (según Romero y Misiego 1995a).

cender el fuego; sobre la misma se practicó un hoyo, que pudo acoger un poste central sobre el que sustentar la techumbre. Al oeste de esta plataforma y bajo una piedra plana se había depositado una inhumación infantil, acompañada aquí, lo que no es frecuente, de su correspondiente, y aún cabría añadir que rico, ajuar, pues lo formaban algunos fragmentos cerámicos, un colgante de hueso y otro de concha, dos brazaletes de bronce de sección rectangular y una arandelita del mismo metal. La segunda vivienda de este momento, análoga a otras excavadas en el Sector I, presenta como decíamos planta rectangular y sus muros, de mampostería en seco, se construyeron con piedras de mediano tamaño; en su interior apareció un piso de arcilla rojiza muy compactada. Se corresponden con las estructuras mencionadas cerámicas a mano, entre las que destacan ahora los cuencos y vasitos carenados decorados con grafito $\mathrm{y}$, en menor medida, pintados (Fig. 7, 2); junto a ellas se documentaron algunos objetos de bronce, tales como una aguja de cabeza enro- llada, un alfiler-fíbula de espirales, dos botones semiesféricos $\mathrm{y}$, formando parte del ajuar de la inhumación infantil, como se ha indicado, dos brazaletes y una pequeña arandela (Romero y Misiego 1995a: 134-138, fig. 3).

Fosilizando en ambos sectores las ocupaciones citadas se atestiguaron las correspondientes al Celtibérico Pleno, con casas de mampostería de planta cuadrangular que, en el caso de la terraza inferior, la más espaciosa como se recordará, se abren a una calle empedrada, con acera de grandes piedras planas, orientada de Este a Oeste. Las cerámicas se fabrican ahora a torno, presentando muchas de ellas sencillos motivos geométricos pintados en color rojo vinoso o negro; cabe mencionar finalmente, entre los objetos metálicos, una fíbula anular hispánica con puente de navecilla y aro de sección romboidal (Romero y Misiego 1995a: 138-139, fig. 4).

Lógicamente proceden de El Castillejo de Fuensaúco las dataciones absolutas con que contamos para este grupo de poblados (Fig. 2, 1), y aunque su número es elevado, pues disponemos de once en total (Romero 1999: 150156), no todas ofrecen idénticas garantías, por lo que nos limitaremos a comentar aquí las más fiables. En principio, las cinco correspondientes al Sector II adolecen de precisión al ser elevadas sus desviaciones estándar; dos de ellas se han desestimado por ofrecer una alta cronología y una tercera viene a fechar con amplísimo margen un momento previo a la construcción de la acera de la calle comentada. Las dos restantes se refieren al depósito ritual localizado bajo la cabaña excavada en la roca y al final de las siguiente ocupación, respectivamente, habiéndose obtenido, dada su semejanza estadística, la media combinada de ambas; la nueva fecha así conseguida viene a indicar, calibrada a dos sigmas, que la vida del poblado durante el Primer Hierro se habría desarrollado en este sector entre mediados del siglo VIII e inicios del IV cal. a.C., aunque pudiera precisarse - de tener en cuenta el intervalo de mayor probabilidad, ligeramente superior al 60 por 100 , dentro de dicho rango de máxima confianza- entre finales del siglo VII e inicios del IV cal. a.C., lo cual parece ajustarse más a la propuesta que, partiendo de criterios estrictamente arqueológicos, se hizo en su momento (Romero y Misiego 1995a: 134 y 138). 
Por desgracia ninguna de las dataciones C-14 de que disponemos para el Sector I se refiere a la cabaña circular excavada en la roca que describíamos líneas arriba, ya que las seis con que contamos se refieren a una ocupación que se presume posterior y contemporánea, en parte al menos, a la segunda del Sector II, pues al igual que aquella cuenta con construcciones cuadrangulares de mampostería. Cinco de ellas se refieren a sus inicios y la sexta a su final, y dado que todas son, al igual que las comentadas anteriormente, estadísticamente semejantes, se ha trabajado con su media combinada; las diferentes posibilidades que ello ofrece, según se prescinda o no de algunas de estas fechas por entenderlas fallidas o escasamente precisas, permite fijar dicha ocupación, calibrada la media a dos sigmas y en el mejor y más amplio de los casos, en el concreto espacio de tiempo de unos cincuenta años que media entre el último tercio del siglo $\mathrm{V}$ y el primero del IV cal. a.C.

\section{EI mundo funerario}

En el estado actual de la investigación carecemos, como queda dicho, de la más mínima información sobre las manifestaciones funerarias de los habitantes de los castros de la serranía norte, lo cual resulta especialmente significativo si tenemos en cuenta la evidente vinculación con el horizonte del Hierro de tradición de Campos de Urnas del Valle del Ebro. Dichas relaciones, como también queda comentado, se detectan en diferentes aspectos de su cultura material y, muy particularmente, en las formas y decoraciones de sus cerámicas, pudiendo llegar a insinuarse incluso en relación con el sistema defensivo de las piedras hincadas, pero, según lo señalado, tales influencias no llegaron a afectar nunca, al menos en el caso de los castros de la serranía, al mundo funerario.

Las vagas noticias que poseemos sobre el particular se limitan a una serie de estructuras tumuliformes localizadas extramuros de los castros del Alto del Arenal de San Leonardo y del Zarranzano, cuya limpieza y excavación resultaron infructuosas (Romero y Misiego 1995b: 71), y a la posible presencia de dos estructuras similares, conteniendo al parecer sendas incineraciones en urna, en una zona marginal de El Castillo de El Royo (Eiroa 1984-1985: 201). Con todo, la necrópolis, recientemente descubierta, de San Pedro, en Oncala, en la cabecera del río Linares, afluente del Alhama, muy próxima a la divisoria entre el Ebro y el Duero (Tabernero, Sanz y Benito 2010: 391-395), viene a confirmar la presencia del ritual incinerador en la zona con anterioridad al horizonte que venimos analizando; algo que había sido señalado ya para la zona de Guadalajara a partir de los datos aportados por la necrópolis de Herrerías, cuyas fases I y II remiten a un momento que se ha situado en el Bronce Final - a partir de las dataciones de C14 (fases I y II) y los paralelos cerámicos (fase II) - , vinculándolas a grupos de Campos de Urnas del Ebro (Cerdeño, Marcos y Sagardoy 2002; Cerdeño et al. 2004).

En cualquier caso, el ritual funerario característico de los Campos de Urnas, la incineración, está plenamente implantado en las tierras del Alto Duero desde el siglo VI a.C., haciendo su aparición con él uno de los elementos culturales que mejor contribuyen a delimitar, entre los siglos VI-II/I a.C., el territorio celtibérico del Alto Duero: las necrópolis (García-Soto 1990; Lorrio 1997: 111). Tales necrópolis se dispersan, en esencia, por el centro y sur de la provincia de Soria; y si a ellas han de asimilarse tanto las identificadas en el oriente segoviano como las de la zona sur del ámbito burgalés, han de excluirse, por contra, otras que, como la soriana de Alpanseque, aconsejan por sus características ser vinculadas a los cementerios del Alto Tajo-Alto Jalón, estudiados en otro trabajo de este mismo volumen, entre los que se integran los también sorianos de Monteagudo de las Vicarías, Almaluez, El Valladar, en Somaén, o El Vado de la Lámpara, en Montuenga. Por lo común, se ubican en zonas abiertas, vegas o llanuras de ligera pendiente, resultando habitual su proximidad a cursos de agua.

Aun cuando la relación necrópolis-poblado no pueda determinarse en muchas ocasiones, lo cierto es que los cementerios se localizan al exterior y en los alrededores de los hábitats, ocupando un espacio, para el que cabe suponer un carácter sagrado, que resultaría visible desde estos, de los que están separados por distancias inferiores al kilómetro y medio, y por lo común de entre ciento cincuenta y trescientos metros. 
Desconocemos así la ubicación de los poblados que habrían de vincularse a los cementerios sorianos de La Mercadera o Quintanas de Gormaz; sin embargo, los trabajos de prospección han permitido localizar los relacionados con las necrópolis, asimismo sorianas, de Los Cantos, en Cubo de la Solana, La Requijada de Gormaz y posiblemente San Martín de Ucero, $\mathrm{y}$ han llegado a ser excavados parcialmente, incluso, los poblados del Cerro del Castillo y el Alto de San Pedro, asociados, respectivamente, a la necrópolis segoviana de La Dehesa de Ayllón y a la burgalesa de El Pradillo de Pinilla Trasmonte. Por lo que se refiere a las de Viñas de Portuguí y Carratiermes podemos suponer, con cierta verosimilitud, que el antiguo hábitat se ubicara en el mismo solar donde posteriormente surgirían, respectivamente, las ciudades arévacas de Uxama y Tiermes.

Ocasionalmente sabemos de la existencia de más de una necrópolis para una misma comunidad, como sucede con el oppidum de Uxama, al que en época Celtibérica Tardía se adscribirían dos cementerios: el ya citado de Viñas de Portuguí, cuyo origen cabría considerar anterior al de la aparición del núcleo urbano como tal, y el de Fuentelaraña, más reciente. Por otra parte, la existencia de diferentes sectores dentro de un mismo cementerio está confirmada en $\mathrm{Ca}$ rratiermes, donde se han identificado al menos dos zonas de enterramiento, separadas entre sí por una franja, libre de sepulturas al parecer, de unos doscientos metros; en uno de ellos ha podido apreciarse, incluso, la existencia de una estratigrafía horizontal, con las sepulturas de mayor antigüedad ocupando el área meridional y las más modernas los flancos septentrional y occidental.

Algunos de los cementerios celtibéricos de la Meseta Oriental presentan una peculiar ordenación interna del espacio funerario, exclusiva del referido sector a lo largo de toda la Edad del Hierro, consistente en la disposición alineada de las tumbas, generalmente señalizadas con estelas, formando calles paralelas. Aunque en su mayoría se localizan en el Alto Tajo-Alto Jalón, se conocen algunos ejemplos de tan peculiar organización en el ámbito del Alto Duero, caso de las necrópolis de La Requijada de Gormaz y Alpanseque, aunque la referida en último lugar se vincule cultural- mente, tal y como hemos señalado, con las del Alto Henares. Con todo, esta disposición no es en absoluto generalizable a la totalidad de las necrópolis celtibéricas, ya que, por más que se utilicen estelas para señalizar las sepulturas, como ocurre en la zona del Alto Duero en las de Carratiermes o Ucero, carecen, por lo común y aparentemente, de cualquier tipo de orden. No obstante, el análisis de los ajuares ha permitido establecer, en ciertos casos, la existencia de una articulación interna; así, en La Mercadera las tumbas con espada aparecen agrupadas en cuatro núcleos diferentes (fig. 8, 1), localizándose el conjunto más numeroso de las mismas en la zona central de la necrópolis $\mathrm{y}$, en torno a él, sepulturas carentes de ajuar en su mayoría (Lorrio 1997: 118).

Al igual que en el caso citado de La Mercadera, todos estos cementerios evidencian desde su aparición indicios de jerarquización social, proporcionando junto a tumbas provistas de armas o caracterizadas por contener adornos de bronce, otras carentes de cualquier elemento de ajuar. Además, las necrópolis del Alto Duero, ofrecen, respecto a lo observado entre los cementerios del Alto Tajo-Alto Jalón o a otros contemporáneos de la Meseta Occidental, una mayor proporción de tumbas provistas de armas, aunque sin llegar a testimoniarse las ricas panoplias documentadas en necrópolis como Aguilar de Anguita o Alpanseque. Los datos obtenidos, en este sentido, a partir del estudio de los ajuares de La Mercadera, donde un 44 por 100 de las sepulturas pertenecerían a guerreros, o de Ucero, con un porcentaje ligeramente inferior del 34,7 por 100 , vienen a corroborar las noticias antiguas sobre el carácter preferentemente militar de los cementerios de Viñas de Portuguí o La Requijada, excavados en la segunda década del siglo XX, o del peor conocido de La Revilla; ello pudiera deberse, muy posiblemente, a que estos cementerios no recibieran a todos los sectores de la población, pues, como pone de manifiesto una vez más el de La Mercadera, parecen faltar muchos de los individuos del nivel social menos favorecido (Fig. 8, 2) (Lorrio 1990: 50). En este sentido conviene traer a colación las inhumaciones infantiles en el interior de los poblados, ritual característico de los grupos de Campos de Urnas del Noreste, que se atestigua en el centro de la 


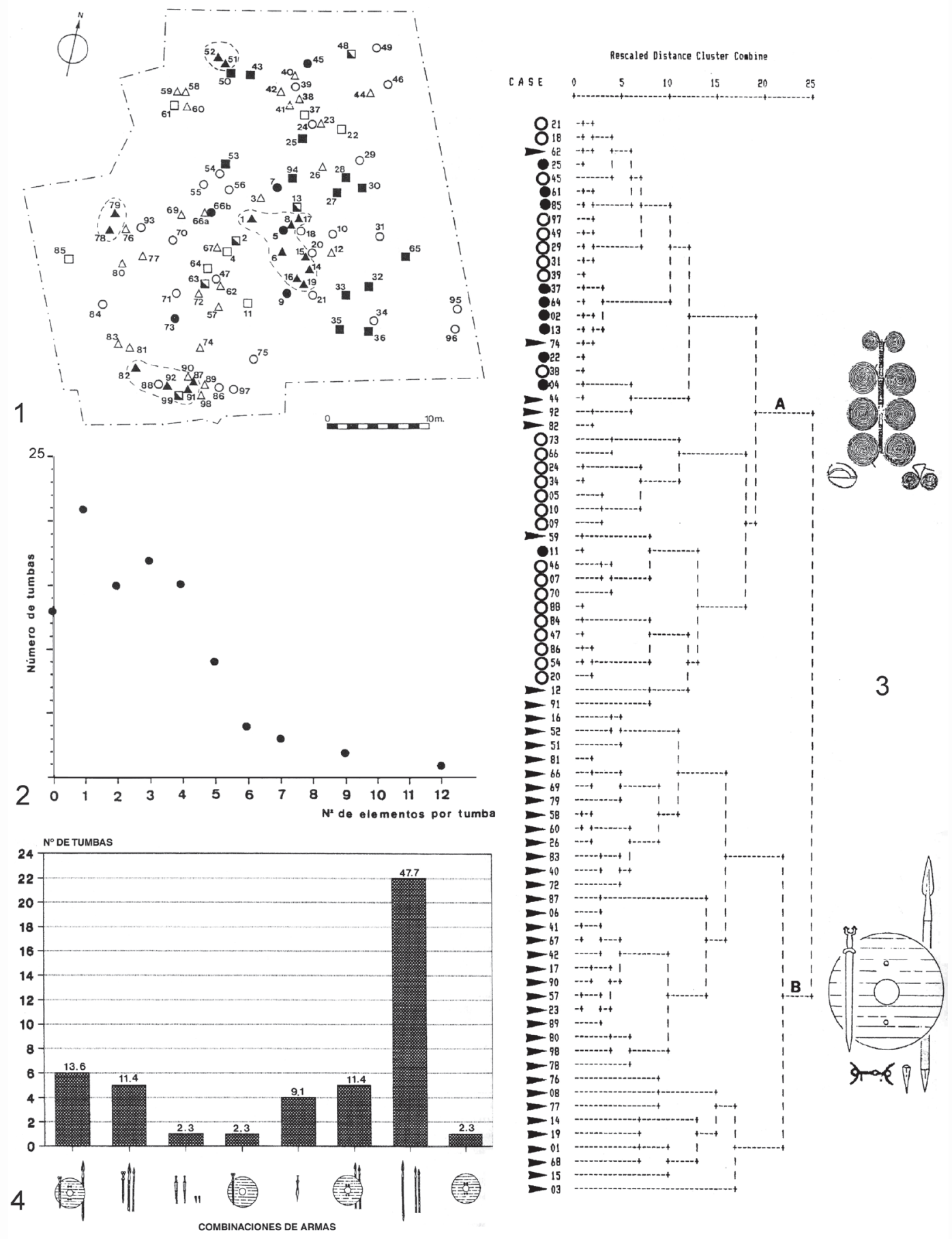

Figura 8.- La Mercadera: 1, plano de la necrópolis con indicación de la articulación social a partir del grado de complejidad de los ajuares (las diferentes áreas individualizadas lo han sido a partir de la concentración de tumbas provistas de espadas o puñales - triángulos en negro — ; por su parte, las tumbas sin ajuar — cuadrados negros - aparecen igualmente concentradas); 2, distribución de la 'riqueza' de las sepulturas, a partir de la cuantificación del número de objetos que integran los ajuares; 3 , dendrograma del análisis de conglomerados de los ajuares (el grupo A incluye las tumbas con adornos - círculos blancos-, los que carecen de objetos 'sexualmente' significativos — puntos negros - y algunos provistos de armas — triángulos-, mientras el B recoge sólo tumbas con armamento); 4, tipos de ajuares militares (según Lorrio 1990 y 1997). 
cuenca del Duero en la cultura del Soto (Delibes et al. 1995: 78-79) y luego será habitual en el mundo ibérico (Gusi y Muriel 2008), no faltando en el territorio que nos ocupa como demuestra el ejemplo de El Castillejo de Fuensaúco, ya citado, donde se halló el enterramiento de un niño bajo el suelo de una vivienda circular adscrita a la segunda ocupación del poblado (Romero y Misiego 1995a: 136-137).

En cualquier caso y como se ha indicado anteriormente, las proporciones de sepulturas de guerreros documentadas en el Alto Duero resultan muy superiores a las observadas en el Alto Tajo-Alto Jalón, detectándose, por otro lado, en el ámbito del Alto Tajo y a partir del siglo IV a.C., un proceso de empobrecimiento en sus ajuares, que llevará incluso a la desaparición del armamento en los mismos, inexistente entre los cementerios del Alto Duero.

El momento inicial de estas necrópolis, adscribible al Celtibérico Antiguo - $c a$. mediados del siglo VI-mediados del V a.C.--, se caracteriza por la presencia de ajuares militares que conviven con otros provistos, principalmente, de adornos broncíneos (Fig. 9). El armamento está representado por largas puntas de lanza, con fuerte nervio central y aletas estrechas, regatones, a veces de gran longitud, y cuchillos curvos; faltan, en cambio, las espadas y los puñales (Argente et al. 1992; Lorrio 1997: 152156), aunque el reciente hallazgo en la necrópolis de Los Cantos, en Cubo de la Solana, de un fragmento descontextualizad de espada con recazos en forma de dos orificios en la zona de la hoja próxima a la empuñadura, similar a la recuperada en la tumba 1 de la necrópolis de Can Canyís (Tabernero, Sanz y Benito 2010: 397, fig. 3), permita plantear el uso excepcional de este tipo de armas durante esta etapa; se trata de una pieza asimilable al tipo de lengüeta plana rectangular y botón terminal, habiéndose propuesto una fecha para el ejemplar catalán de en torno al segundo cuarto del siglo VI a.C. (Farnié y Quesada 2005: 84 y 131). Además, se depositan en las tumbas fíbulas de codo tipo Meseta, de doble resorte con puente filiforme, de cinta, rómbico u oval, anulares hispánicas y de pie vuelto con botón terminal, broches de cinturón de escotaduras y de uno a tres garfios, pectorales de espirales y de placa, brazaletes de aros múltiples, fusayolas, etc. Las urnas, realizadas a mano, presentan perfiles en $\mathrm{S} y$, a veces, pie elevado, cubriéndose por lo general con cuencos troncocónicos. Esta fase está atestiguada en un buen número de necrópolis de las cuencas altas del Tajo, del Jalón y del Duero, territorio éste último donde se localizan los cementerios de Carratiermes, Ucero, La Mercadera, Ayllón y Pinilla Trasmonte.

Tras dicho estadio inicial, se desarrolla sin solución de continuidad una fase de plenitud, que adscribimos al Celtibérico Pleno - $c a$. mediados del siglo V-finales del III a.C.te la cual los ajuares ofrecen, por regla general, una mayor modernidad que los registrados durante este mismo período en los cementerios de las altas tierras del norte de Guadalajara y sur de Soria con ellos relacionados (Fig. 9). Esto resulta particularmente evidente en el caso del armamento, pues si la espada debió de incorporarse pronto a los ajuares funerarios, por lo común responde a modelos evolucionados; así ocurre con las diversas variantes del tipo de antenas, cuyos contextos permiten fecharlas en los siglos IV-III a.C., aunque los modelos de frontón, carentes de asociaciones significativas en esta zona, bien pudieran ofrecer una fecha más elevada. Faltan en estas necrópolis las armas broncíneas de parada - cascos, pectorales y grandes chatones de escudo- y no resulta frecuente el hallazgo de soliferrea. Esta fase se encuentra reflejada en las necrópolis de Carratiermes, Ucero, La Requijada de Gormaz, Quintanas de Gormaz, La Revilla de Calatañazor y Viñas de Portuguí, aunque sea la de La Mercadera (Taracena 1932: 5-31; Lorrio 1990) la que permite realizar un estudio más completo de la misma.

En efecto, el análisis de los ajuares de esta necrópolis soriana tantas veces citada permite individualizar dos grandes grupos, caracterizados, en general, por la presencia de armas, en un caso, y de adornos espiraliformes y brazaletes, en el otro (Fig. 8, 3). Las sepulturas del primer grupo evidencian una gran variabilidad en los elementos que integran los equipos armamentísticos, pues se documentan desde tumbas con la panoplia completa hasta las que ofrecen como único testimonio una, dos y, excepcionalmente, tres puntas de lanza, que son las que constituyen el grupo más numeroso, o las que presentan un sencillo cuchillo (fig. 8, 4). Des- 


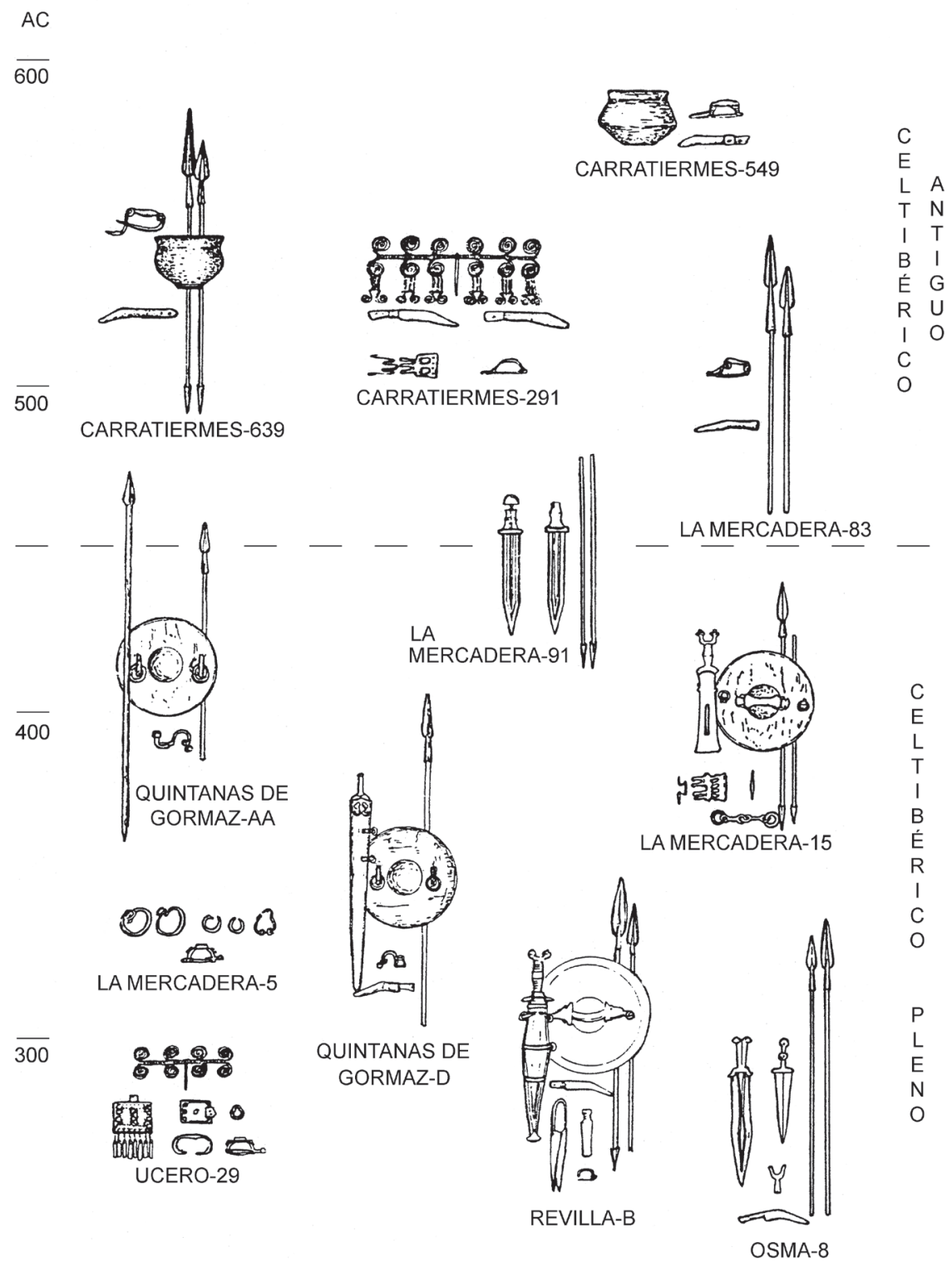

Figura 9.- Cuadro evolutivo de los ajuares funerarios de las necrópolis del Alto Duero durante el Celtibérico Antiguo y Pleno.

tacan, por su parte, en el segundo grupo los elementos de adorno integrados por espirales, generalmente pertenecientes a pectorales, los brazaletes de bronce de aros múltiples, los pares de pulseras de hierro y, muy particularmente, un interesante conjunto de piezas de plata, formado por pulseras, pendientes, torques, fíbulas, etc., ya que la presencia de dicho metal resulta poco frecuente en las necrópolis celtibéricas - excepción hecha del aplicado en los broches y espadas damasquinadas-, aunque se conozcan algunos otros objetos recuperados en ciertos ajuares contemporáneos de Ucero, Gormaz y Carratiermes. También merece una mención especial el hallazgo de elementos relacionados con el banquete, concretamente asadores, en una tumba de guerrero de La Mercadera. Sorprende, por el contrario, en este mismo cementerio la escasez de vasijas cerámicas 
(Lorrio 1990: 47), ya que de un total de cien sepulturas documentadas en el mismo, tan sólo quince contaban con un vaso, que haría las veces de urna cineraria; se trata en su mayoría de piezas realizadas a mano, entre las que destacan los ejemplares con decoración a peine (Lorrio 1990: 49), siendo por lo tanto muy reducida, y puede decirse que puramente testimonial, la presencia de la cerámica fabricada a torno. Según se deduce de la cronología proporcionada por los diferentes elementos de ajuar, y principalmente por las fíbulas, esta necrópolis podría datarse a partir del segundo cuarto del siglo VI a.C., tuvo su máximo apogeo más de siglo y medio más tarde, a lo largo del IV a.C., y dejó de utili- zarse al poco de ello, hacia finales de dicha centuria o en el primer cuarto de la siguiente.

A lo largo del siglo III a.C. se detecta la continuidad en el uso de buena parte de las necrópolis citadas; es entonces cuando se incorporan a los ajuares de forma generalizada las espadas de tipo La Tène y los modelos de antenas más evolucionados, como son los tipos Atance y Arcóbriga, junto a los puñales, principalmente de los tipos de frontón, biglobular y, en menor medida, Monte Bernorio, modelo éste último conocido en la Meseta Oriental desde el siglo IV a.C., así como alguna que otra falcata, testimonio de los limitados contactos que, en este momento y por lo que se refiere al armamento, debieron de existir con el área ibérica.

\section{REFERENCIAS BIBLIOGRÁFICAS}

Abarquero Moras, F.J. (2005): Cogotas I. La difusión de un tipo cerámico durante al Edad del Bronce. Arqueología en Castilla y León, Monografías 4, Junta de Castilla y León, Valladolid.

Alfaro Peña, E. (2005): Castillejos y Villares. Modelos de poblamiento antiguo en el interior del Sistema Ibérico. Asociación Cultural "Soria Edita", Soria.

Almagro-Gorbea, M. (1986-87): Los Campos de Urnas en la Meseta. Actas del Coloquio Internacional sobre la Edad del Hierro en la Meseta Norte. Zephyrus, XXXIX-XL: 31-47.

Almagro-Gorbea, M. (1993): Los Celtas en la Península Ibérica: origen y personalidad cultural. Los celtas: Hispania y Europa (M. Almagro-Gorbea, G. Ruiz Zapatero, eds.), Actas de El Escorial, Madrid: 121-173.

Almagro-Gorbea, M. (1994): Urbanismo de la Hispania "céltica". Castros y Oppida del centro y occidente de la Península Ibérica. Castros y Oppida en Extremadura (M. Almagro-Gorbea, A.M ${ }^{\text {a }}$ Martín Bravo, eds.), Complutum Extra, 4, Madrid: 13-75.

Alonso, N.; Junyent, E.; López, J.B. (2010): Arbeca. La fortaleza dels Vilars. Guies del Museu d'Arqueologia de Catalunya, Museu d'Arqueologia de Catalunya, Barcelona, 2a ${ }^{\text {a }}$ ed.

Argente Oliver, J.L.; Díaz Díaz, A.; Bescos Corral, A.; Alonso Lubias, A. (1992): Los conjuntos protoceltibéricos de la Meseta Oriental: ejemplos de la necrópolis de Carratiermes (Montejo de Tiermes, Soria). Trabajos de Prehistoria, 49: 295-325.

BAchiller GiL, J.A. (2008): Los fosos de los castros sorianos: realidad o ficción. Vegueta, 10: 25-48.

Bachiller Gil, J.A.; Ramírez SÁnchez, M.E. (1993): Contribución al estudio de los pueblos prerromanos del alto Duero: pelendones. Vegueta, 1: 31-46.

Bachiller Martínez, J.Ma.; Sancho de Francisco, Ma.C. (1990): Introducción al estudio del espacio geográfico soriano. Arevacon, 16, Asociación de amigos del Museo Numantino, Soria.

Barroso Bermejo, R.M. (1993): El Bronce final y la transición a la Edad del Hierro en Guadalajara. WadAl-Hayara, 20: 9-44.

Bellver Garrido, J.A. (1992): Estudio zooarqueológico de las cabañas circulares de El Castillejo de Fuensaúco. Actas del II Symposium de Arqueología Soriana, Diputación Provincial de Soria, Soria, vol. I: 325-332.

Borobio Soto, M. J. (1985): Carta Arqueológica. Soria. Campo de Gómara. Diputación Provincial de Soria, Soria.

Bosch Gimpera, P. (1932): Etnologia de la Península Ibèrica. Barcelona.

BRonk Ramsey, C. (2009): Bayesian analysis of radiocarbon dates. Radiocarbon, 51(1): 337-360. 
Burillo Mozota F. (Coord.) (1990): Necrópolis celtibéricas. II Simposio sobre los Celtíberos. Institución "Fernando El Católico", Zaragoza.

Burillo Mozota, F. (1998): Los celtíberos. Etnias y estados. Crítica, Barcelona.

Burillo Mozota F.; Ortega Ortega J.M. (1999): El proceso de formación de las comunidades campesinas en el Sistema Ibérico (1400-400 a.C.): algunas consideraciones acerca del concepto de "ruptura". El origen del mundo celtibérico. Actas de los Encuentros sobre el origen del mundo celtibérico (J.A. Arenas Esteban, Ma .V. Palacios Tamayo, coords.), Ayuntamiento de Molina de Aragón, Guadalajara: 123-141.

Calavia Redondo, M. (1990): El espacio soriano. Geografía de Castilla y León. 8. Las comarcas tradicionales (A. Cabo, F. Manero, dirs.), Ámbito, Valladolid: 140-176.

Cerdeño Serrano, Ma .L.; García Huerta, R. (1990): Las necrópolis de incineración del Alto Jalón y el Alto Tajo. Necrópolis celtibéricas. II Simposio sobre los Celtíberos (F. Burillo Mozota, coord.), Institución "Fernando El Católico", Zaragoza: 75-92.

Cerdeño, M.'a.; Marcos, F.; Sagardoy, T. (2002): Campos de Urnas en la Meseta Oriental: nuevos datos sobre un viejo tema. Trabajos de Prehistoria, 59 (2): 135-147.

Cerdeño, M.'L.; Rodríguez, G.; Folgueira, M.; Hernández, M. ${ }^{a}$ C.; Corraliza, R. (2004): Novedades culturales y metodológicas en la necrópolis de Herrería (Guadalajara). Novedades Arqueológicas Celtibéricas (M. Barril, A. Rodero, coords.), Museo Arqueológico Nacional, Madrid: 43-62.

Delibes de Castro, G.; Romero Carnicero, F. (1992): El último milenio a.C. en la Cuenca del Duero. Reflexiones sobre la secuencia cultural. Paleoetnología de la Península Ibérica (M. Almagro-Gorbea, G. Ruiz Zapatero, eds.), Complutum, 2-3: 233-258.

Delibes de Castro, G.; Romero Carnicero, F.; Morales Muñzz, A. (eds.) (1995): Arqueología y medio ambiente: El primer milenio a.C. en el Duero Medio. Junta de Castilla y León, Valladolid.

Delibes de Castro, G.; Romero Carnicero, F.; Sanz Mínguez, C.; Escudero Navarro, Z.; San Miguel Maté, L. C. (1995): Panorama arqueológico de la Edad del Hierro en el Duero medio. Arqueología y medio ambiente: El primer milenio a.C. en el Duero Medio (G. Delibes de Castro, F. Romero Carnicero, A. Morales Muñiz, eds.), Junta de Castilla y León, Valladolid: 50-146.

Eiroa García, J. J. (1981): Moldes de arcilla para fundir metales procedentes del Castro Hallstáttico de El Royo (Soria). Zephyrus, XXXII-XXXIII: 181-193.

Eiroa García, J.J. (1984-1985): Aportación a la cronología de los castros sorianos. Homenaje al Prof. Gratiniano Nieto, vol. I, Cuadernos de Prehistoria y Arqueología de la Universidad Autónoma de Madrid, 11-12: 197-203.

Esparza Arroyo, A. (1980): Nuevos castros con piedras hincadas en el borde occidental de la Meseta. Actas do Seminário de Arqueología do Noroeste peninsular, Guimarães, vol. II: 71-86.

Esparza Arroyo, A. (1986): Los castros de la Edad del Hierro del noroeste de Zamora. Instituto de Estudios Zamoranos Florián de Ocampo y Diputación de Zamora, Zamora.

Esparza Arroyo, A. (2003): Castros con piedras hincadas del Oeste de la meseta y sus aledaños. Chevauxde-frise i fortificació en la primera edat del ferro europea (N. Alonso, E. Junyent, A. Lafuente, J.B. López, coords.), Universidad de Lleida, Lleida: 155-178.

Farnié Lobensteiner, C.; Quesada SAnz, F. (2005): Espadas de hierro, grebas de bronce: símbolos de poder e instrumentos de guerra a comienzos de la edad del hierro en la Península Ibérica. Serie Monografías del Museo de Arte Ibérico de El Cigarralejo 2, Comunidad Autónoma de la Región de Murcia, Consejería de Educación y Cultura, Murcia.

FERnÁNDEZ-Posse, Ma .D. (1998): La investigación protohistórica en la Meseta y Galicia. Síntesis, Madrid.

García-Soto Mateos, E. (1990): Las necrópolis de la Edad del Hierro en el alto valle del Duero. Necrópolis celtibéricas. II Simposio sobre los Celtíberos (F. Burillo Mozota, coord.), Institución "Fernando El Católico", Zaragoza: 13-38.

Gailledrat, E.; Moret. P. (2003): La fortificatión de Pech Maho (Sigean, Aude) et le probleme de ses pierres plantées. Chevaux-de-frise i fortificació en la primera edat del ferro europea (N. Alonso, E. Junyent, A. Lafuente, J.B. López, coords.), Universidad de Lleida, Lleida: 119-133.

Garrido-Pena, R. (2000): El Campaniforme en la Meseta Central de la península ibérica (c. 2500-2000 $A C$.). BAR International Series 892, Oxford. 
G.I.P. (Grup d'Investigació Prehistòrica de la Universitat de Lleida) (2003): Caballos y hierro. El campo frisio y la fortaleza de "Els Vilars d'Arbeca" (Lleida, España), siglos VIII-IV a.n.e. Chevaux-de-frise i fortificació en la primera edat del ferro europea (N. Alonso, E. Junyent, A. Lafuente, J.B. López, coords.), Universidad de Lleida, Lleida: 233-274.

Gómez-Barrera, J.A. (1992): Grabados rupestres postpaleolíticos del Alto Duero. Caja Salamanca y Soria y Junta de Castilla y León, Soria.

Gusi, F.; Muriel, S. (2008): Panorama actual de la investigación de las inhumaciones infantiles en la Protohistoria del sudoeste mediterráneo europeo. Nasciturus, infans, puerulus vobis mater terra: la muerte en la infancia (F. Gusi, S. Muriel, C. Olària, eds.), Diputació de Castelló, Servei d'Investigacions Arqueològiques i Prehistòriques, Castelló: 257-329.

JimÉnez-Guijarro, J. (2010): Cazadores y campesinos. La neolitización del interior de la Península Ibérica. Bibliotheca Archaeologica Hispana, 31, Real Academia de la Historia, Madrid.

Jimeno Martínez, A. (1984a): Estado actual de la investigación del Eneolítico y la Edad del Bronce en la provincia de Soria. Actas del I Symposium de Arqueología Soriana, Diputación Provincial de Soria, Soria: $25-50$.

Jimeno Martínez, A. (1984b): Los Tolmos de Caracena (Soria) (Campañas de 1977, 1978 y 1979). Nuevas bases para el estudio de la Edad del Bronce en la zona del Alto Duero. Excavaciones Arqueológicas en España, 134. Madrid.

Jimeno Martínez, A. (1985): Prehistoria. Historia de Soria (J. A. Pérez-Rioja, dir.), Centro de Estudios Sorianos, Soria, t. I: 83-122.

Jimeno Martínez, A.; Arlegui Sánchez, M. (1995): El poblamiento en el Alto Duero. Poblamiento Celtibérico. III Simposio sobre los Celtíberos (F. Burillo Mozota, coord.), Institución "Fernando El Católico", Zaragoza: 93-126.

Jimeno Martínez, A.; Fernández Moreno, J.J. (1991): Los Tolmos de Caracena (Soria). (Campañas de 1981 y 1982). Aportación al Bronce Medio de la Meseta. Excavaciones Arqueológicas en España, 161. Madrid.

Jimeno Martínez, A.; Fernández Moreno, J.J. (1992): El poblamiento desde el Neolítico a la Edad del Bronce: constantes y cambios. Actas del II Symposium de Arqueología Soriana, Diputación Provincial de Soria, Soria, vol. I: 69-101.

Jimeno Martínez, A.; Martínez Naranjo, J. P. (1999): El inicio de la Edad del Hierro en el nudo hidrográfico Alto Jalón-Alto Duero. El origen del mundo celtibérico. Actas de los Encuentros sobre el origen del mundo celtibérico (J. A. Arenas Esteban y Mª. V. Palacios Tamayo, coords.), Ayuntamiento de Molina de Aragón, Guadalajara: 165-189.

Jimeno Martínez, A.; Fernández Moreno, J. J.; Revilla Andía, Ma ${ }^{a}$ L. (1988): Asentamientos de la Edad del Bronce en la provincia de Soria: Consideraciones sobre los contextos culturales del Bronce Antiguo. Noticiario Arqueológico Hispánico, 30: 85-118.

Lorrio Alvarado, A. J. (1990): La Mercadera (Soria): Organización social y distribución de la riqueza en una necrópolis celtibérica. Necrópolis celtibéricas. II Simposio sobre los Celtíberos (F. Burillo Mozota, coord.), Institución "Fernando El Católico", Zaragoza: 39-50.

Lorrio Alvarado, A. J. (1997): Los Celtíberos. Complutum Extra, 7. Alicante. (2a edición ampliada y actualizada, Bibliotheca Archaeologica Hispana 25, Real Academia de la Historia, Madrid, 2005).

Lorrio Alvarado, A. J.; Gómez Ramos, P.; Montero Ruiz, I.; Rovira Llorens, S. (1999): Minería y metalurgia celtibérica. Economía. IV Simposio sobre Celtíberos (F. Burillo Mozota, coord.), Institución "Fernando El Católico", Zaragoza, 161-180.

Morales Hernández, F.; Bachiller Gil, J. A. (2007): La primera Edad del Hierro en la provincia de Soria: el yacimiento de "El Palomar" (Almajano). Celtiberia, 101: 359-396.

Moret, P. (1996): Les fortifications ibériques. De la fin de l'Âge du Bronze à la conquête romaine. Collection de la Casa de Velázquez, 56, Madrid.

Ocejo Herrero, A. (1995): La situación geográfica de los pelendones, según Claudio Ptolomeo. Poblamiento Celtibérico. III Simposio sobre los Celtíberos (F. Burillo Mozota, coord.), Institución "Fernando El Católico", Zaragoza: 477-493. 
Pascual Díez, A.C. (1991): Carta Arqueológica. Soria. Zona Centro. Diputación Provincial de Soria, Soria.

Quesada SAnz, F. (2003): De los fosos de Troya a la línea Sigfrido. Las "piedras hincadas" en el contexto de la historia de las fortificaciones. Chevaux-de-frise i fortificació en la primera edat del ferro europea $(\mathrm{N}$. Alonso, E. Junyent, A. Lafuente, J.B. López, coords.), Universidad de Lleida, Lleida: 69-100.

RAmírez RAmíREZ, Mª L. (1999): La casa circular durante la primera Edad del Hierro en el Valle del Duero. Numantia. Arqueología en Castilla y León, 7: 67-94.

Revilla Andía, Ma . L. (1985): Carta Arqueológica. Soria. Tierra de Almazán. Diputación Provincial de Soria, Soria.

Revilla Andía, Maa L.; Jimeno Martínez, A. (1986-87): La dualidad de la cultura castreña en la provincia de Soria. Actas del Coloquio Internacional sobre la Edad del Hierro en la Meseta Norte. Zephyrus, XXXIX-XL: 87-101.

Romero Carnicero, F. (1984a): La Edad del Hierro en la provincia de Soria. Estado de la cuestión. Actas del I Symposium de Arqueología Soriana, Diputación Provincial de Soria, Soria: 51-121.

Romero Carnicero, F. (1984b): La Edad del Hierro en la serranía soriana: los castros. Studia Archaeologica, 75. Valladolid.

Romero Carnicero, F. (1985): La primera Edad del Hierro. El afianzamiento de la sedentarización y la explotación intensiva del medio. Historia de Castilla y León. 1. La prehistoria del Valle del Duero (J. Valdeón, dir.), Ámbito, Valladolid: 82-103.

Romero Carnicero, F. (1989): Algunas novedades sobre los castros sorianos. Diez años de arqueología soriana (1978-1988) (J. L. Argente Oliver, coord.), Museo Numantino y Junta de Castilla y León, Soria: 49-58.

Romero Carnicero, F. (1991): Los castros de la Edad del Hierro en el norte de la provincia de Soria. Studia Archaeologica, 80, Valladolid.

Romero Carnicero, F. (1992): Los antecedentes protohistóricos. Arquitectura de piedra y barro durante la primera Edad del Hierro. Arquitectura popular en Castilla y León. Bases para un estudio (J.M. Báez Mezquita, coord.), Universidad de Valladolid, Valladolid: 175-211.

Romero Carnicero, F. (1999): Orígenes y evolución del grupo castreño de la Sierra Norte soriana. La aportación de la cronología radiocarbónica. El origen del mundo celtibérico. Actas de los Encuentros sobre el origen del mundo celtibérico (J. A. Arenas Esteban, Mª. V. Palacios Tamayo, coords.), Ayuntamiento de Molina de Aragón, Guadalajara: 143-164.

Romero Carnicero, F. (2003): Piedras hincadas en el oriente meseteño. Chevaux-de-frise i fortificació en la primera edat del ferro europea (N. Alonso, E. Junyent, A. Lafuente, J. B. López, coords.), Universidad de Lleida, Lleida: 179-208.

Romero Carnicero, F.; Jimeno Martínez, A. (1993): El valle del Duero en la antesala de la Historia. Los grupos del Bronce Medio-Final y Primer Hierro. Los celtas: Hispania y Europa (M. Almagro-Gorbea, G. Ruiz Zapatero, eds., Actas de El Escorial, Madrid: 175-222.

Romero Carnicero, F.; Misiego Tejeda, J.C. (1992): Los orígenes del hábitat de la Edad del Hierro en la provincia de Soria. Las cabañas de El Castillejo de Fuensaúco. Actas del II Symposium de Arqueología Soriana, Diputación Provincial de Soria, Soria, vol. I: 307-324.

Romero Carnicero, F.; Misiego Tejeda, J.C. (1995a). Desarrollo secuencial de la Edad del Hierro en el Alto Duero: El Castillejo (Fuensaúco, Soria). Poblamiento Celtibérico. III Simposio sobre los Celtíberos (F. Burillo Mozota, coord.), Institución "Fernando El Católico", Zaragoza: 127-139.

Romero Carnicero, F.; Misiego Tejeda, J.C. (1995b): La Celtiberia Ulterior. Análisis del substrato. Poblamiento Celtibérico. III Simposio sobre los Celtíberos (F. Burillo Mozota, coord.), Institución "Fernando El Católico", Zaragoza: 59-81.

Romero Carnicero, F.; Ruiz Zapatero, G. (1992): La Edad del Hierro. Problemas, tendencias y perspectivas. Actas del II Symposium de Arqueología Soriana, Diputación Provincial de Soria, Soria, vol. I: 103-120.

Ruiz Zapatero, G. (1977): Fortificaciones del castro hallstáttico de Valdeavellano (Soria). Celtiberia, 53: $83-92$.

Ruiz Zapatero, G. (1984): Cogotas I y los primeros "Campos de Urnas" en el Alto Duero. Actas del I Symposium de Arqueología Soriana, Diputación Provincial de Soria, Soria: 169-185. 
Ruiz Zapatero, G. (1995): El substrato de la Celtiberia Citerior. El problema de las invasiones. Poblamiento Celtibérico. III Simposio sobre los Celtíberos (F. Burillo Mozota, coord.), Institución "Fernando El Católico", Zaragoza: 25-40.

Ruiz Zapatero, G. (2003): Las fortificaciones de la Primera Edad del Hierro en la Europa templada. Chevaux-de-frise i fortificació en la primera edat del ferro europea, (N. Alonso, E. Junyent, A. Lafuente, J. B. López, coords.), Universidad de Lleida, Lleida: 13-34.

Ruiz Zapatero, G.; Lorrio, A.J. (1999): Las raíces prehistóricas del mundo celtibérico. El origen del mundo celtibérico. Actas de los Encuentros sobre el origen del mundo celtibérico (J. A. Arenas Esteban, Mª. V. Palacios Tamayo, coords.), Ayuntamiento de Molina de Aragón, Guadalajara: 21-36.

Ruiz Zapatero, G.; Lorrio Alvarado, A.J. (2005): La Celtiberia: entre la complejidad y la afinidad. Acta Paleohispánica 9, IX Coloquio sobre Lenguas y Culturas Paleohispánicas (F. Beltrán, J. Velaza, eds.), Palaeohispanica, 5, Institución "Fernando el Católico", Zaragoza: 657-684.

Tabernero Galán, C.; Sanz Aragonés, A.; Benito Batanero, J. P. (2010): Necrópolis de cremación en el nordeste de Soria. Ritos y Mitos. VI Simposio sobre Celtíberos (F. Burillo Mozota, ed.), Estudios Celtibéricos, 6, Fundación Segeda - Centro de Estudios Celtibéricos, Zaragoza: 391-402.

Taracena Aguirre, B. (1929): Excavaciones en las provincias de Soria y Logroño. Memorias de la Junta Superior de Excavaciones y Antigüedades, 103, Madrid.

Taracena Aguirre, B. (1932): Excavaciones en la provincia de Soria. Memorias de la Junta Superior de Excavaciones y Antigüedades, 119, Madrid.

Taracena Aguirre, B. (1933): Tribus celtibéricas. "Pelendones". Homenagem a Martins Sarmento, Guimarães: $393-401$.

Taracena Aguirre, B. (1941): Carta Arqueológica de España. Soria. Consejo Superior de Investigaciones Científicas, Madrid.

Taracena Aguirre, B. (1954): Los pueblos celtibéricos. Historia de España (R. Menéndez Pidal, dir.), Espasa-Calpe, Madrid, vol. I-3: 195-299. 